\title{
Evaluation of the toxicity of graphene derivatives on cells of the lung luminal surface
}

\author{
Lenke Horváth ${ }^{a, b}$, Arnaud Magrez ${ }^{a, c}$, Marko Burghard ${ }^{d}$, Klaus Kern ${ }^{d}$, László Forró ${ }^{a}$, \\ Beat Schwaller ${ }^{b, *}$ \\ ${ }^{a}$ Laboratory of Physics of Complex Matter (LPMC), Ecole Polytechnique Fédérale de Lausanne, 1015 Lausanne, Switzerland \\ ${ }^{\mathrm{b}}$ University of Fribourg, Anatomy, Department of Medicine, Route Albert-Gockel 1, CH-1700 Fribourg, Switzerland \\ c Crystal Growth Facility, Ecole Polytechnique Fédérale de Lausanne, 1015 Lausanne, Switzerland \\ d Max-Planck-Institut für Festkörperforschung, Heisenbergstrasse 1, 70569 Stuttgart, Germany
}

\section{Introduction}

Graphene derivatives (GD) have recently been put under the scientific spotlight due to their exceptional properties, such as high electronic conductivity, good thermal stability and excellent mechanical strength. Graphene is a two-dimensional mono-atomic thick material made of carbon atoms and thus it has a remarkably different shape compared to one-dimensional carbon nanotubes (CNT). Recent progress has shown that graphene-based materials can have a profound impact in a broad range of applications, e.g., structural nanocomposites [1,2], battery electrodes [3], supercapacitors $[1,4]$ and biomedicine [5-8]. It is anticipated that the number and use of these materials will significantly increase in coming years.

Among the $>15,000$ research papers published in the last 5 years, studies related to the health and safety issues and interaction of GD with cells remain a small contribution to the total scientific literature, and have only recently become the subject of intensive investigation. Previous studies focused mainly on in vitro toxicity tested in bacteria and in mammalian cells. Results from different studies using similar approaches often diverge from one to another, and authors even draw opposite conclusions. While GD are suggested to be ideally suited for future biomedical applications due to their increased antimicrobial/antibacterial characteristics

\footnotetext{
* Corresponding author: Fax: +41 263009733.

E-mail address: beat.schwaller@unifr.ch (B. Schwaller).
} 
$[9,10]$, others not only fail to detect bactericidal/bacteriostatic properties, but instead report GD as a general growth enhancer [11]. In regard to mammalian cell toxicity in vitro, the first study in PC12 (pheochromocytoma-derived) cells compared the effect of graphene with single-walled CNT [12]. Both pure carbon-based nanomaterials induced concentration-dependent neural toxicity; and CNT were clearly more toxic than graphene. These findings further emphasize the essential role of the shape of nanomaterials with respect to the adverse biological impact (acute cytotoxicity). Additional studies have been performed with cultured cells deriving from lung epithelium [10,13-15], fibroblasts [16,17], platelets [18], erythrocytes [16], monocytes and macrophages [14,19-21]. Moreover, the putative risk of GD to cause adverse health effects in vivo through inflammatory reactions/responses in the lung was assessed in only a small number of studies [14,20].

Thus, results from previous studies do not allow definitive conclusions to be drawn and are rather starting points for further experimental verification and mechanistic elucidation of the cytotoxicity/biocompatibility of GD. Of additional consideration, the risk for generating adverse health effects may be reduced by surface functionalization as was shown in other studies, e.g., with polyethylene glycol [5] or chitosan [22]. The latter studies focused on future biomedical applications. In the field of graphene toxicity, there is emerging literature on potential health risks, but the limited published work has not yet allowed to reaching a consensus with respect to their toxicity and putative adverse health effects.

This study is motivated by the need for a better understanding of the mechanisms of GD-cell interactions at the alveolar epithelium/luminal interface. In the scope of this work the in vitro cellular response and interaction of A549 epithelial cells and RAW 264.7 macrophages-our respective models for primary cellular targets following inhalation of GD (Fig. 1) was examined. We carried out cell viability tests and investigated the implication of the apoptotic cell death pathway. Furthermore, the interaction of graphene oxide (GO) with the aforementioned cells and its subsequent internalization was analyzed by electron microscopy and finally, the intracellular reactive oxygen species (ROS)-inducing capacity of GO was tested. Our results show two-dimensional GD to exhibit mild short-term toxicity on both epithelial cells and macrophages, clearly lesser than the toxic action of the one-dimensional CNT. The phagocytic macrophages as well as the non-phagocytic epithelial cells internalized GO sheets by an endocytic pathway in a size-independent manner without causing a discernible adverse morphological change. Finally, we observed short-lived generation of ROS as a result of nanomaterial-cell interactions; this may be of importance in the later onset of putative genotoxicity following exposure to GD.

\section{Experimental}

2.1. Synthesis and characterization of nanomaterials and preparation of nanomaterial stock solutions

For our studies, few-layer graphene oxide (GO) sheets were prepared from graphite flakes of $20-\mu \mathrm{m}$ size $(99.99 \%$ purity;
Sigma-Aldrich, Munich, Germany) via the Hummers method [23]. Analysis of a larger number of AFM images revealed GO sheets with lateral dimensions (i.e., the maximum dimensions of the material; $d_{\text {proj}}$ ) of $100 \mathrm{~nm}$ to $5 \mu \mathrm{m}$ (average: $1 \mu \mathrm{m})$ and heights in the range of 1.1-15 $\mathrm{nm}$. Approximately $80 \%$ of the sheets displayed a height of $1.1 \pm 0.2 \mathrm{~nm}$ corresponding to true monolayers, and multiples of this value were found for the other particles. This data was used to estimate, whether GO sheets were within the size range of the respirable fraction ending up in alveolar regions. For this, the aerodynamic diameter $\left(d_{\mathrm{ae}}\right)$ was estimated using the equation described in Schinwald et al. [20],

$d_{a e}=\sqrt{\frac{9 \cdot \pi}{16} \cdot \frac{\rho}{\rho_{0}} \cdot d_{\text {proj }} \cdot t}$

where $t$ is the thickness of the GO sheets, $d_{\text {proj }}$ represents the projected diameter and $\rho_{0}$ and $\rho$ are the unit density and density, respectively. For an average GO sheet $\left(d_{\text {proj: }}: 1 \mu \mathrm{m}, t=1-\right.$ $10 \mathrm{~nm}, \rho \sim 2$ ), the aerodynamic diameter is in the range of 20-200 nm, respectively and thus in the respirable fraction as reported in [24]. The same was also observed for graphene-family nanomaterials with diameters in the range of $0.5-25 \mu \mathrm{m}$ and a layer thickness of 1-30 layers [19]. Purity was assessed by energy-dispersive X-ray spectroscopy (EDX) and near edge X-ray absorption fine structure analysis (NEXAFS); GO contained different types of oxygenated functional groups as reported in Pacile et al. [25], and no metal impurities were detected (data not shown). The oxygen content was in the order of 40 at.\% in the GO sheets and approximately 10 at.\% in rGO similar as reported before [26]. More details on the material characterization were reported previously [27].

Compared to pristine graphene, GO is heavily oxygenated bearing hydroxyl and epoxy groups in the plane, in addition to carbonyl and carboxyl groups located at the sheet edges. Hence, GO is highly hydrophilic and readily exfoliated in water due to electrostatic repulsion (negative surface charges). GO sheets were chemically reduced to rGO using hydrazine [27]; size ranges (diameter, thickness) and purity were essentially identical to the ones observed for GO. Multiwalled CNT were produced as described previously [28,29].

The nanomaterial suspensions were prepared as reported in our previous studies. All solutions were prepared as aqueous stock solutions by several consecutive sonication and stirring steps and contained $200 \mu \mathrm{g} / \mathrm{mL}$ nanoparticles and $200 \mu \mathrm{g} /$ mL Tween 80.

\subsection{Cell culture}

We used two cell lines for the experiments: A549 cells of human origin, used as the in vitro model for type II lung epithelium cells, commonly employed in lung toxicity assays [2832], and RAW 264.7 mouse peritoneal macrophage cells for modeling the alveolar macrophages. Both cell lines were obtained from American Type Culture Collection (ATCC, USA, catalogue numbers: CCL-185 and TIB-71, respectively). The cells were cultured in RPMI 1640 medium (Invitrogen) supplemented with $10 \%$ heat-inactivated fetal bovine serum and antibiotics $(10,000 \mathrm{U} / \mathrm{mL}$ penicillin, $10 \mathrm{mg} / \mathrm{mL}$ streptomycin; 

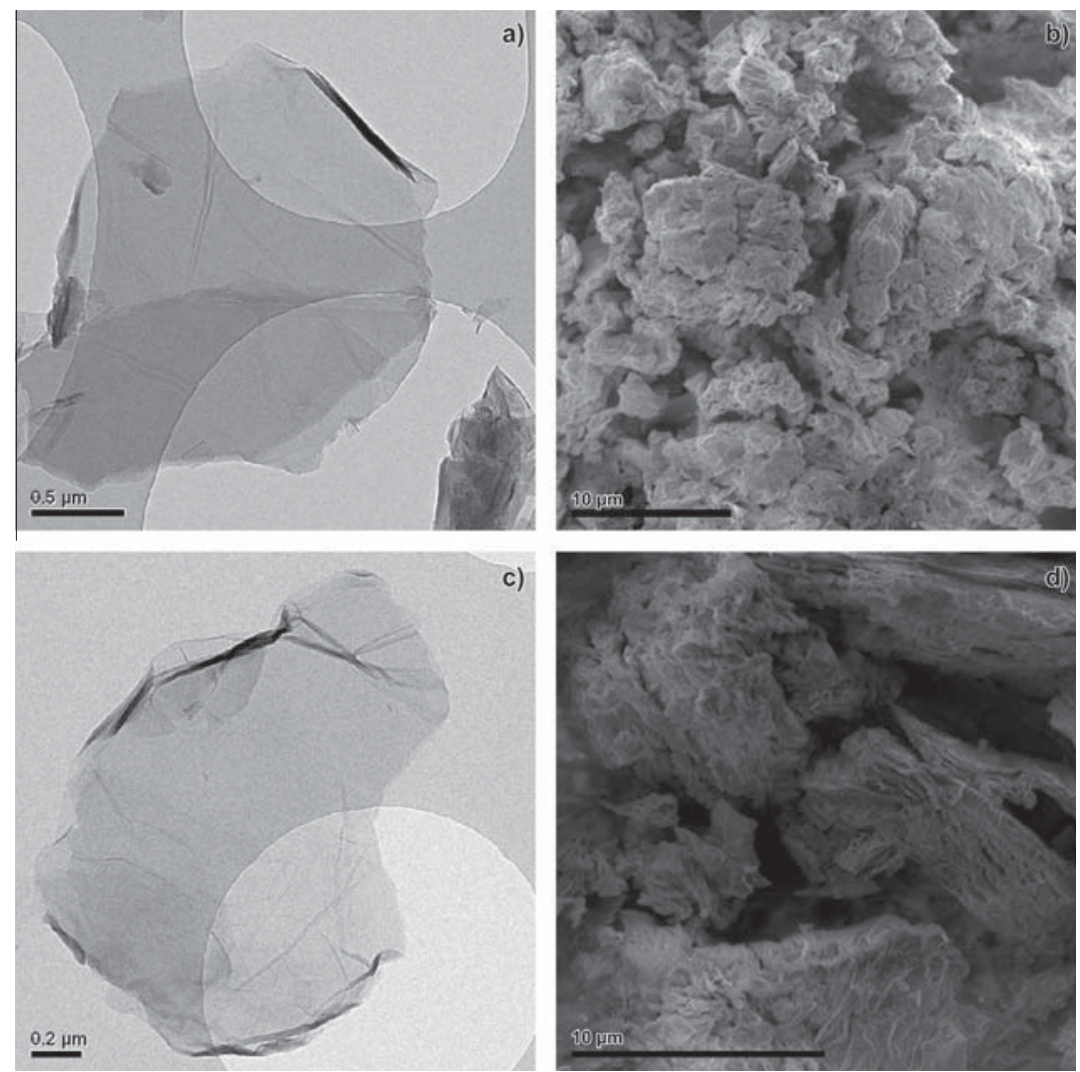

Fig. 1 - Transmission electron micrograph $(a, c)$ of a graphene oxide and reduced graphene oxide flake, respectively and the corresponding scanning electron micrographs $(b, d)$ showing the homogeneity of the material. Both graphene oxide and reduced graphene oxide are in the same size range.

Invitrogen). They were maintained in a humidified atmosphere containing $5 \% \mathrm{CO}_{2}$ at $37^{\circ} \mathrm{C}$ and subcultured when reached near-confluence. For the cytotoxicity measurements cells were seeded in 96 -well culture plates. After an overnight incubation (once adhesion was verified), $100 \mu \mathrm{L}$ of fresh medium containing the corresponding amount of nanomaterials (NM) was added to the cells. Cells were exposed to 0.02, 0.2, $2 \mu \mathrm{g} / \mathrm{mL} \mathrm{NM}$ (with $2 \mu \mathrm{g} / \mathrm{mL}$ Tween 80; Sigma-Aldrich) and/or $20 \mu \mathrm{g} / \mathrm{mL}$ nanomaterials (with $20 \mu \mathrm{g} / \mathrm{mL}$ Tween 80) for up to 5 days. All parallel cultures serving as untreated controls were also supplemented with fresh medium that contained either 2 or $20 \mu \mathrm{g} / \mathrm{mL}$ Tween 80 , respectively. The above-mentioned NM concentrations correspond to a surface density of $0.0125,0.125,1.25$ and $12.5 \mu \mathrm{g} \mathrm{NM} / \mathrm{cm}^{2}$, therefore, for easier comparison with other studies we use the latter measure, i.e., weight per surface area to present our results. Each experiment was repeated at least three times with a minimum of three replicates of the same material and NM concentration.

\subsection{Cytotoxicity assays}

For the determination of cell number, cell viability, cell metabolic status and cell proliferation, all important parameters related to cytotoxicity, different, and moreover, complementary assays were used as reported before [25]. Initial effects of NM were evaluated by the MTT (3-(4,5-dimethylthiazol-2yl)-2,5-diphenyltetrazolium bromide) assay (Thiazolyl blue tetrazolium bromide; Sigma-Aldrich) that reports the combined effects of proliferation (number of viable cells) and cellular metabolic activity [33]. The yellow tetrazolium MTT is reduced by cells maintaining normal metabolic function, by the action of mitochondrial dehydrogenase enzymes in the presence of pyridine nucleotide cofactors that viable, metabolically active cells produce in the respiratory chain. The resulting intracellular purple formazan crystals were solubilized by the addition of dimethylsulfoxide (DMSO, $100 \mu \mathrm{L} /$ well) and the formazan concentration was finally quantified using an ELISA-plate spectrophotometer by measuring the absorbance at $540 \mathrm{~nm}$ (Dynatec MRX, Dynatec Produkte AG, Switzerland). The procedure was identical to the one used previously $[28,30]$, where we had shown that solubilization of formazan crystals by DMSO is quantitative and not susceptible to artifacts caused by the lumping of formazan crystals with $\mathrm{NM}$ as reported before [34]. In addition, we tested whether GO alone might catalyze the conversion of the tetrazolium solution to formazan. For this, the MTT solution was incubated for $3 \mathrm{~h}$ with GO, rGO and CNT (0.0125-12.5 $\mu \mathrm{g} /$ $\mathrm{cm}^{2}$ ). Samples were centrifuged, rinsed with PBS and resuspended in DMSO to check whether formazan had formed on the NM. After centrifugation, O.D. $540 \mathrm{~nm}$ values of the supernatant were found to be identical (in all NM samples) to the one obtained in absence of any NM (data not shown).

The number/viability of cells following NM exposure was further investigated by two fluorometric assays: the 
fluorometric DNA assay [35] and the fluorometric microculture cytotoxicity assay (FMCA) [36]. In the former, the determination of the DNA quantity is based on the increase of the fluorescence of bisbenzimide (Hoechst 33258) nucleic acid stain upon selective binding to the cellular dsDNA. The amount of DNA per sample (in a well of a 96-well plate) was quantitatively determined and was found to be directly proportional to the number of cells. At time points of interest, the culture medium was removed from the samples, attached cells were washed with phosphate-buffered saline (PBS) and frozen at $-80^{\circ} \mathrm{C}$. After the first freeze/thaw cycle, $100 \mu \mathrm{L} /$ well of double distilled water was added to each well and the 96well plates were incubated for $60 \mathrm{~min}$ at RT on a rotating shaker; the cell lysates were obtained by two freezing/thawing cycles. After the second cycle, the cell lysates were transferred to black microtiter plates (Perkin Elmer AG). To the lysates, $100 \mu \mathrm{L}$ of a Hoechst 33258 (Sigma-Aldrich) working solution $(20 \mu \mathrm{g} / \mathrm{mL}$ in TNE buffer: $10 \mathrm{mM}$ Tris, $1 \mathrm{mM}$ EDTA, $2 \mathrm{M} \mathrm{NaCl}, \mathrm{pH}$ 7.4) was added to each sample. The cell lysate mixtures were then incubated in the dark for $30 \mathrm{~min}$ at RT on a shaker and measured on a VICTOR X3 multilabel plate reader (Perkin Elmer AG) at $\lambda_{\mathrm{Ex}} / \lambda_{\mathrm{Em}}=350 / 460 \mathrm{~nm}$. In comparison to fluorescence signals obtained in the absence of GD (defined as $100 \%)$, even at the highest concentration (12.5 $\mu \mathrm{g} /$ $\mathrm{cm}^{2}$ ), the presence of GD had no significant effect on the fluorescence signal intensity (101 $\pm 2 \%$; n.s.), thus no fluorescence quenching by GD was detected. In the FMCA assay, cells are incubated with the cell-permeant, non-fluorescent probe fluorescein diacetate (FDA) that is hydrolyzed to fluorescein by the esterase activity of cells with an intact plasma membrane [36-38], thus the emitted fluorescence is proportional to the number of viable cells. For the measurements, cells were cultured in black 96-well microtiter plates with or without NMs, respectively. At various time points, the plates were centrifuged for $5 \mathrm{~min}$ (200g), once washed with PBS $(200 \mu \mathrm{L} /$ well) and centrifuged once more. After aspiration of the PBS solution, $100 \mu \mathrm{L}$ FDA (Sigma-Aldrich) working solution (10 $\mu \mathrm{g} / \mathrm{mL}$ FDA in buffer: $125 \mathrm{mM} \mathrm{NaCl}, 25 \mathrm{mM}$ HEPES pH 7.4) was added per well. Microtiter plates were incubated at $37{ }^{\circ} \mathrm{C}$ in a humidified atmosphere of $5 \% \mathrm{CO}_{2}$ for $40 \mathrm{~min}$. The quantity of released fluorescein was determined on a VICTOR $\mathrm{X} 3$ multilabel plate reader (Perkin Elmer AG) at $\lambda_{\mathrm{EX}} / \lambda_{\mathrm{Em}}=485 /$ $520 \mathrm{~nm}$. A slight, yet non-significant decrease to $94 \pm 2 \%$ (n.s.) fluorescence signal intensity at the highest GD concentration tested $\left(12.5 \mu \mathrm{g} / \mathrm{cm}^{2}\right)$ was observed; the fluorescence signal intensity in the absence of GD is defined as $100 \%$. Thus, differences in fluorescence signal intensity in the FMCA assay were considered as genuine GD-mediated effects on cells, if the differences compared to untreated control cells were at least $10 \%$.

\subsection{Alexa Fluor ${ }^{\circledR} 488$ Annexin V/dead cell apoptosis assay}

The Annexin V assay is a classical technique for detecting apoptosis and is based on the high affinity and selectivity of Annexin $\mathrm{V}$ to the externalized phosphatidylserine (PS) that is one of the earliest features during apoptotic cell death. Once PS is exposed to the outer environment, it remains on the cell surface throughout the dying process. Annexin V can be conjugated to fluorophores (e.g., Alexa Fluor ${ }^{\circledR}$ 488) and once bound to externalized PS, makes the identification of cells in the early phase of apoptosis possible. Therefore, when used in conjunction with the propidium iodide (PI) vital dye, measuring cell membrane integrity, early apoptotic cells (Annexin $\mathrm{V}+$ only) can be distinguished from late apoptotic/ necrotic cells (Annexin V+/PI+, show both green and red fluorescence, respectively). The population of live cells shows only a low level of Annexin V staining of the cellular membrane. For qualitative assessment of live, apoptotic and dead cells, $8 \times 10^{3}$ A549 epithelial cells and RAW 264.7 macrophages were seeded into 24-well plates and incubated overnight at $37{ }^{\circ} \mathrm{C}, 5 \% \mathrm{CO}_{2}$. The cells were further exposed to 0.0125 , $0.125,1.25$ and $12.5 \mu \mathrm{g} \mathrm{NM} / \mathrm{cm}^{2}$ in addition to untreated cells (control) for the desired time period. 4 days post-exposure, Alexa Fluor ${ }^{\circledR} 488$ Annexin V/Dead cell assay (Invitrogen) was performed according to the manufacturer's protocol. Briefly, the cells were washed with ice-cold PBS, loaded with $150 \mu \mathrm{L} /$ well Annexin Binding Buffer containing $10 \mu \mathrm{L}$ Annexin V conjugate and $2 \mu \mathrm{L}$ PI (100 $\mu \mathrm{g} / \mathrm{mL}$ working solution) and incubated for $15 \mathrm{~min}$ at RT. After washing and reloading the samples with 1x Annexin Binding Buffer, the fluorescence was observed using appropriate filters for green and red fluorescence (fluorescence excitation/emission maxima: Alexa Fluor ${ }^{\circledR} 488$ Annexin V: 488/499 nm; PI: 535/617 nm). Digital images were taken with an inverted fluorescent microscope Leica AF7000 (Leica Microsystems CMS GmbH, Mannheim, Germany).

\subsection{Reactive oxygen species (ROS) detection}

The formation of intracellular ROS was assessed by employing the fluorescent assay, DCF. The original method was described by Wan et al. [39], and has been already used in other studies on NM toxicity $[12,31,40]$ and moreover, it is the assay recommended by the NANOMMUNE consortium http://ki.projectcoordinator.net/projectweb/490599f501abc/ Index.html). The non-fluorescent 2',7'-dichlorodihydrofluorescein diacetate ( $\mathrm{H}_{2} \mathrm{DCF}-\mathrm{DA}$, Molecular Probes) is a cell permeable dye due to its diacetate group. Upon enzymatic deacetylation by intracellular esterases, it is accumulated within the cell and converted by ROS-mediated oxidation to a highly fluorescent $2^{\prime}, 7^{\prime}$-dichlorofluorescein (DCF). Oxidation of the probe can be detected by monitoring the increase in fluorescence.

For the assessment of ROS formation, $8 \times 10^{4}$ RAW 264.7 and $5 \times 10^{4}$ A549 cells were plated in 96-well culture plates and allowed to attach overnight. Subsequently, the cells were treated with $0.0125,0.125,1.25$ and $12.5 \mu \mathrm{g} / \mathrm{cm}^{2}$ NMs. After incubation for different time periods from $30 \mathrm{~min}$ to $24 \mathrm{~h}$, cells were washed with pre-warmed Hank's Balanced Salt Solution (HBSS, Invitrogen), loaded with $50 \mu \mathrm{M} \mathrm{H} \mathrm{H}_{2}$ DCF-DA for $30 \mathrm{~min}$ at $37^{\circ} \mathrm{C}$ and the washing step with HBSS was repeated in order to eliminate the excess of the unreacted probe. After adding $100 \mu \mathrm{L}$ HBSS/well, the fluorescence intensity was measured at $485 \mathrm{~nm}$ excitation and $520 \mathrm{~nm}$ emission wavelength on a VICTOR X3 multilabel plate reader, in which the fold-increase in relative fluorescence intensity was expressed as the ratio of NM-treated vs. untreated control cells. The effect of the antioxidant $\mathrm{N}$-acetyl-cysteine (NAC; Sigma-Aldrich) was studied on RAW 264.7 cells plated at densities $5 \times 10^{4}$ and 
$8 \times 10^{4}$ cells/well in microplates. Cells were pre-treated with $10 \mathrm{mM}$ NAC for $1 \mathrm{~h}$ and further incubated for $1 \mathrm{~h}$ with the GO suspensions containing the same NAC concentration. The subsequent steps are identical with the aforementioned procedure. NAC was prepared as a $0.1 \mathrm{M}$ stock solution in PBS $(\mathrm{pH}=7.4)$, filter-sterilized and stored at $4{ }^{\circ} \mathrm{C}$.

\subsection{Transmission electron microscopy}

The NM toxicity-associated morphological alterations at the cellular/subcellular level, the cell-NM interactions on the surface of the cell membrane and the NM localization within the cytosol and cell compartments was examined with electron microscopy. For these experiments $5 \times 10^{5}$ A549 and $7 \times 10^{5}$ RAW 264.7 cells were seeded on PET track-etched membranes with $3 \mu \mathrm{m}$ pores (BD Biosciences) and exposed to GO suspensions of $12.5 \mu \mathrm{g} / \mathrm{cm}^{2}$ for 1, 2, 3 and $96 \mathrm{~h}$, respectively. Specimen preparation of cells for TEM included 10 major steps: surface cleaning, primary fixation, rinsing, secondary fixation, rinsing, dehydration, infiltration with a transitional solvent, preembedding I (infiltration with resin-solvent mixture), preembedding II (infiltration with resin), flat embedding, and sectioning with staining. Briefly, the surface of the cells grown on membranes was cleaned by rinsing them with pre-warmed $0.1 \mathrm{M} \mathrm{Na}$-cacodylate buffer $(\mathrm{pH}=7.4)$. The samples were chemically prefixed in a $2 \%$ paraformaldehyde (PFA) $/ 2.5 \%$ GDA solution ( $90 \mathrm{~min})$, gently rinsed by three changes of $0.1 \mathrm{M}$ Na-cacodylate buffer, cut out from the inserts and subsequently postfixed in $1 \% \mathrm{OsO}_{4}\left(1 \mathrm{~h}, 4^{\circ} \mathrm{C}\right)$. Rinsing was repeated as previously, and the samples were kept in a fresh change of $0.1 \mathrm{M} \mathrm{Na}$-cacodylate buffer overnight at $4{ }^{\circ} \mathrm{C}$. Next, samples were dehydrated in a graded series of ethanol at RT. Once the dehydration process was finished (in 100\% EtOH) the alcohol was substituted by propylene oxide (PO), miscible with the embedding medium. The immersion of specimens in PO twice for $10 \mathrm{~min}$ was sufficient prior to the pre-embedding procedure. The first pre-embedding procedure included immersion in PO/epoxy resin at different ratios of: 3:1, 1:1 and 1:3 (v/v) for $1 \mathrm{~h}, \mathrm{RT}$ each. Next, the second pre-embedding step followed, by immersing the samples in pure epoxy resin for $1 \mathrm{~h} 45 \mathrm{~min}$ at RT. The polymerization of the resin was achieved in flat embedding by placing the samples in a drying chamber for $48 \mathrm{~h}$ at $60^{\circ} \mathrm{C}$. Finally, the specimens were cut with a microtome to obtain semi-thin sections $(7 \mu \mathrm{m})$, stained with toluidine blue for $1 \mathrm{~min}$ on a hot plate $\left(60^{\circ} \mathrm{C}\right)$, examined by light microscope to identify the regions of interest for further proceeding with ultramicrotomy. Ultra-thin sections $(70 \mathrm{~nm})$ were picked up onto 75-mesh formvar coated copper grids, contrasted with $5 \%$ uranyl acetate for 20 min and lead citrate for $10 \mathrm{~min}$ and photographed with a Philips CM100 Biotwin transmission electron microscope (magnifications used: $3400 \times, 5800 \times, 7400 \times, 9700 \times$ and 13,500x) using the iTEM software (Olympus Soft Imaging Solutions $\mathrm{GmbH}$ ).

\subsection{Statistical analysis}

Each experiment was repeated at least three times $(n \geqslant 3)$ in triplicates or higher. The results are presented as mean $\pm S D$. Statistical analysis was performed using Student's t-test and differences were considered significant at $p<0.05$.

\section{Results and discussion}

\subsection{Assessment of cellular toxicity}

The effects of GD on the cell number/metabolic activity of epithelial cells and macrophages was assessed by the MTT assay (Fig. 2). In comparison to control cells, MTT signals were clearly decreased in A549 and RAW 264.7 cells exposed to $1.25 \mu \mathrm{g} / \mathrm{cm}^{2} \mathrm{GO}$ and $\mathrm{rGO}$ for 5 days; differences were obvious after 2 and 3 days of treatment in the two cell types, respectively (Fig. 2a,b). At all time points, the decrease in cell number/metabolic activity was similar for GO and rGO in both cell types, and the decrease of MTT signals was stronger in macrophages than in epithelial cells. This can also be observed in the dose-response curves obtained 5 days postexposure (Fig. 2c,d). The lower concentrations of 0.0125 and $0.125 \mu \mathrm{g} / \mathrm{cm}^{2}$ resulted in approximately the same magnitude ( 10-15\% and 35-40\%) of decrease in MTT signal respectively, while the highest dose $\left(1.25 \mu \mathrm{g} / \mathrm{cm}^{2}\right)$ caused a stronger decrease in macrophages of up to $\sim 60 \%$ as compared to only $\sim 40 \%$ in epithelial cells.

To directly address whether the decreased MTT signal after GD treatment was associated with reduced cell number/cell proliferation, the amount of DNA ( cell number) was determined by the fluorometric DNA assay during a period of up to 5 days of exposure in RAW 264.7 cells (Fig. 3). In the dose range of $0.0125-1.25 \mu \mathrm{g} / \mathrm{cm}^{2}$ of either GO or $\mathrm{rGO}$, curves of control and GD-treated cells were essentially identical. Thus, although metabolic activity of GD-treated cells was clearly impaired (Fig. 2), cell proliferation determined by the DNA assay was unaltered.

In order to get a better insight in the putative toxicity of GD, we chose to compare the toxicity profile of GD with that of CNT, a nanomaterial previously tested in several studies $[28,29,41]$. With respect to chemical composition, GD are similar to CNTs. The main difference is their shape: the former being atomically flat graphitic structures, the latter being tubular materials. No significant differences between GO and rGO were seen in the MTT and DNA assays (Figs. 2 and 3).

Since effects on both cell types were essentially identical for GO and rGO (Figs. 2 and 3), further experiments were carried out with GO. During the synthesis of graphene by chemical exfoliation, GO is the first derivative compound. This choice was motivated by the fact that it has higher usage in various applications compared to rGO. In composites functional groups enhance GO distribution and helps at an efficient load transfer to the matrix for reinforcement. GO is also the best material for functionalization as oxygen-containing groups can covalently bind chemicals. Furthermore, we have shown that the presence of oxygen-containing groups on the surface of CNTs enhances their toxic action [29]. All consecutive experiments were additionally performed at a dose of $12.5 \mu \mathrm{g} / \mathrm{cm}^{2}$, because of the apparently low toxicity of GO. This concentration value is still within the range of "low dose" [42]. Thus, the toxicity of GO and f-CNT in A549 and RAW 264.7 cells was determined after 5 days of exposure by the FMCA, DNA and MTT assay (Fig. 4). In line with our previous studies $[28,29,41]$ functionalized CNT (f-CNT) were found to be cytotoxic for epithelial cells as well as for macrophages; the decrease in cell viability (Fig. 4a,d), cell number (Fig. 4b,e) 

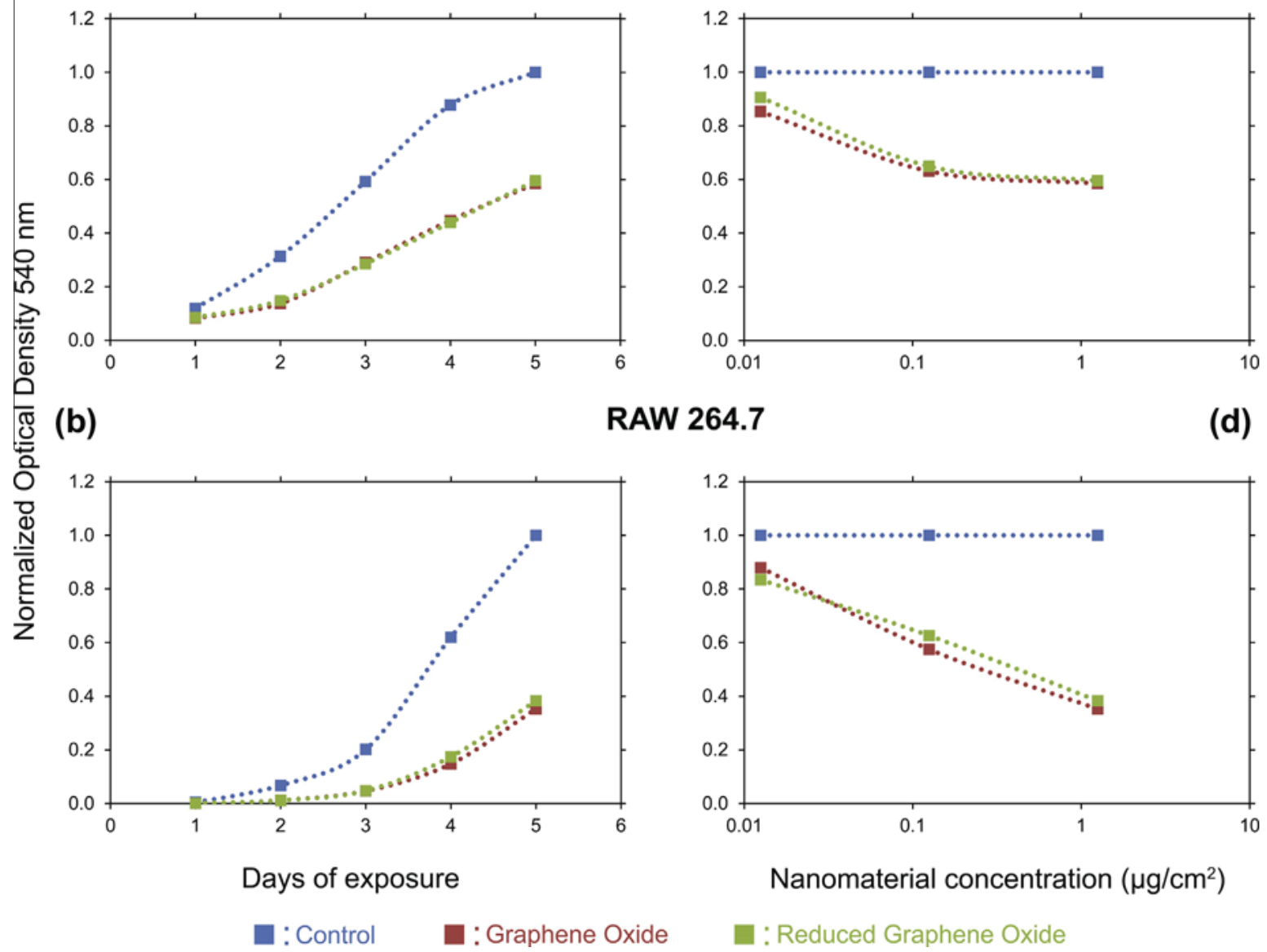

Fig. 2 - Effect of GD on A549 (a, c) and RAW 264.7 cells (b, d) assessed by the MTT assay. (a, b) Normalized average growth curves of A549 and RAW 264.7 cells exposed to graphene oxide and reduced graphene oxide at a $1.25 \mu \mathrm{g} / \mathrm{cm}^{2} \mathrm{dose}$. (c, d) Normalized dose-dependent toxicity of A549 and RAW 264.7 cells treated with graphene oxide and reduced graphene oxide for 5 days. Significant differences $(p<0.05)$ between control and GD-treated cells (GO and rGO) were observed from day 2 on in A549 cells (a) and from day 3 on in RAW 264.7 cells (b). In the dose-response curves (c, d), differences were significant at the two higher concentrations $\left(0.125\right.$ and $\left.1.25 \mu \mathrm{g} / \mathrm{cm}^{2}\right)$ for both materials and both cell types. In addition, in macrophages, rGO treatment with the lowest dose $\left(0.0125 \mu \mathrm{g} / \mathrm{cm}^{2}\right)$ resulted in significantly lower MTT signals.

and cell number/metabolic activity (Fig. 4c,f) was clearly more pronounced at higher $\mathrm{f}$-CNT concentrations. In A549 cells, the effect of GO and f-CNT on viability/proliferation evidenced by the FMCA and DNA assay was rather minor at the two lower concentrations $\left(0.125\right.$ and $\left.1.25 \mu \mathrm{g} / \mathrm{cm}^{2}\right)$ and an effect was mostly observed in the MTT assay. At the highest dose $\left(12.5 \mu \mathrm{g} / \mathrm{cm}^{2}\right)$ also the number of viable cells was decreased (Fig. 4a,b). Of interest, the effects of GO and f-CNT on A549 cells were of similar magnitude in all 3 tests.

In contrast, in macrophages (RAW 264.7) cell number, viability and metabolic activity was much stronger affected by fCNT than by GO. While GO mostly impaired metabolic activity as evidenced in the MTT assay (also compare with Fig. 2) and had a very minor effect on cell number/viability even at the highest dose (Fig. 4d,e), f-CNT strongly reduced the number and viability of macrophages, in parallel to the impaired metabolic activity. These results also confirmed our previous observations that cytotoxicity of nanomaterials is critically dependent on the cell type $[28,41]$.
Since GO had a cytotoxic effect in both cell types, in particular at the highest dose tested $\left(12.5 \mu \mathrm{g} / \mathrm{cm}^{2}\right)$, we investigated the underlying cell death mechanism(s) resulting from GO exposure. Processes contributing to cell loss are primarily apoptotic or necrotic cell death; apoptosis being an active process initiated by extra- or intracellular signals, necrosis referring to a passive form of traumatic cell death that results from acute cellular injury [43]. Therefore, in addition to the previously shown quantitative assays we set out to assess by qualitative means the impact of GO on the cell viability, i.e., to use fluorescence microscopy in combination with appropriate live/dead stains (Annexin V/propidium iodide (PI)). This allows to distinguishing early apoptotic cells (Annexin V-pos. only) from late apoptotic/necrotic cells (Annexin V-pos./PIpos.), while healthy cells show negative staining. A549 and RAW 264.7 cells were treated with GO and rGO (0.0125$12.5 \mu \mathrm{g} / \mathrm{cm}^{2}$ ) for 4 days. Since no apparent differences were observed in cells treated with GO or rGO, images are presented only for GO (Fig. 5; images for rGO are depicted in 


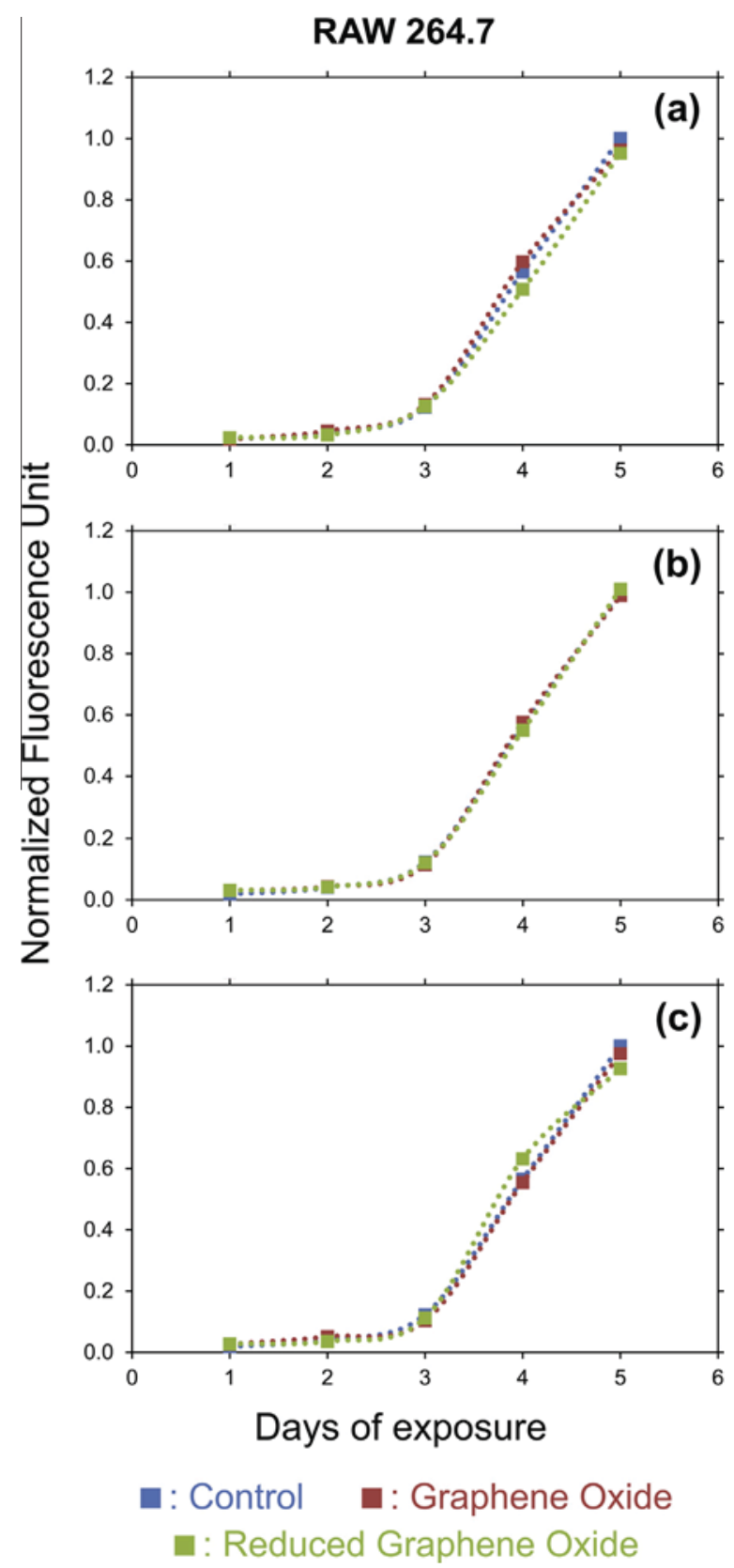

Fig. 3 - Cell proliferation of GD-treated RAW 264.7 cells determined by the fluorometric DNA assay $(a-c)$. Normalized average growth curves of macrophage cells treated with (a) $0.0125 \mu \mathrm{g} / \mathrm{cm}^{2}$, (b) $0.125 \mu \mathrm{g} / \mathrm{cm}^{2}$ and (c) $1.25 \mu \mathrm{g} / \mathrm{cm}^{2}$ graphene oxide and reduced graphene oxide for 5 days. Fluorescence signals (DNA content) are directly proportional to the cell number per sample.

Suppl. Fig. 1). Up to a dose of $1.25 \mu \mathrm{g} / \mathrm{cm}^{2}$, Annexin V-pos. A549 cells were rare, double-stained cells were even rarer, but were found at places, where also deposited GO is visible (Fig. 5a, see merged images). This indicates that GO is rather non-cytotoxic at the concentrations tested. Macrophages were clearly more susceptible to GO-induced cytotoxicity (Fig. 5b). In a concentration-dependent manner, the fraction of Annexin V-pos. and Annexin V/PI-pos. RAW 264.7 cells increased. These findings are in good agreement with quantita- tive results (Fig. 4d, e, f), where a decrease in cell number, viability and metabolic status of GO-treated macrophages was observed. Furthermore, the rare occurrence of PI-pos. only (necrotic) cells indicates that the cell loss of GO-treated macrophages is mostly the result of apoptotic cell death.

\subsection{Uptake of GO by epithelial cells and macrophages}

Apoptosis in cells exposed to GO might be caused by several mechanisms including the interaction with the plasma membrane or as the result of GO internalization. The latter has already been addressed in studies using monolayer cell cultures, e.g., in epithelial, fibroblast and macrophage cells [10,13-15,17,19-21]. While Hu and co-authors [10] found endocytic internalization of GO in A549 epithelial cells, Chang et al. [13] proposed that single-layered GO sheets do not enter this cell type. Moreover, three recent studies reported internalization of graphene sheets in THP-1 $[19,20]$ and RAW 264.7 cells [44], however the translocation of GD to either the cytosol or to subcellular compartments of macrophages is still largely unexplored. The study of Yue et al. [21] addressed the size effect of GO in respect to phagocytic and non-phagocytic cell types reporting that only macrophages were able to internalize GO sheets having lateral dimensions of $350 \mathrm{~nm}$ and $2 \mu \mathrm{m}$ in a size-independent manner. In addition, micron-sized GO induced stronger inflammatory responses, whereas nanosized GO displayed better biocompatibility. Thus, we set out to investigate the fate and localization of the GO used in this study when applied to A549 and RAW 264.7 cells by sedimentation. For this, cells were incubated for 4 days with $12.5 \mu \mathrm{g} /$ $\mathrm{cm}^{2} \mathrm{GO}$ and their intracellular localization pattern and cell morphology was analyzed. A qualitative analysis of low-magnification TEM images revealed the presence of GO or rGO in a considerable fraction of cells, i.e., in the order of $35-45 \%$, the lower value prevalent in A549 epithelial cells, the higher one mostly seen in RAW 264.7 macrophages (data not shown).

Untreated (control) A549 cells showed morphological features characteristic of alveolar epithelial type II cells, such as short and small microvilli on the surface and lamellar body structures within the cytoplasm (Fig. 6a). In GO-treated cells intracellular accumulation of GO sheets of various dimensions was observed (Fig. 6b-d). In all cases the nanomaterial was confined to intracellular vesicles surrounded by an intact membrane indicative of an endocytotic process of uptake. Although some stacks of GO sheets were in close proximity of the nucleus even causing an indent in the nuclear envelope (Fig. 6c,d), the nanomaterial was clearly outside of the nucleus unlike in cells treated with long, straight fibrous materials such as $\mathrm{TiO}_{2}$ nanofilaments or BNNT $[28,30]$. Besides the presence of the membrane-confined GO, no other modification in the morphology or ultrastructure of A549 cells was found when compared to untreated control cells.

The cell surfaces of RAW 264.7 macrophages had many protrusions (pseudopodia, filopodia) that varied in shape; the nucleus had an irregular outline and the rather electron dense cytoplasm showed abundant mitochondria, vesicles and lysosomes at various developmental stages (Fig. 7a). In macrophages exposed to GO, the nanomaterial was internalized and localized within structures surrounded by membranes, likely phago(lyso)somes of varying sizes, similar to the case 
(a)
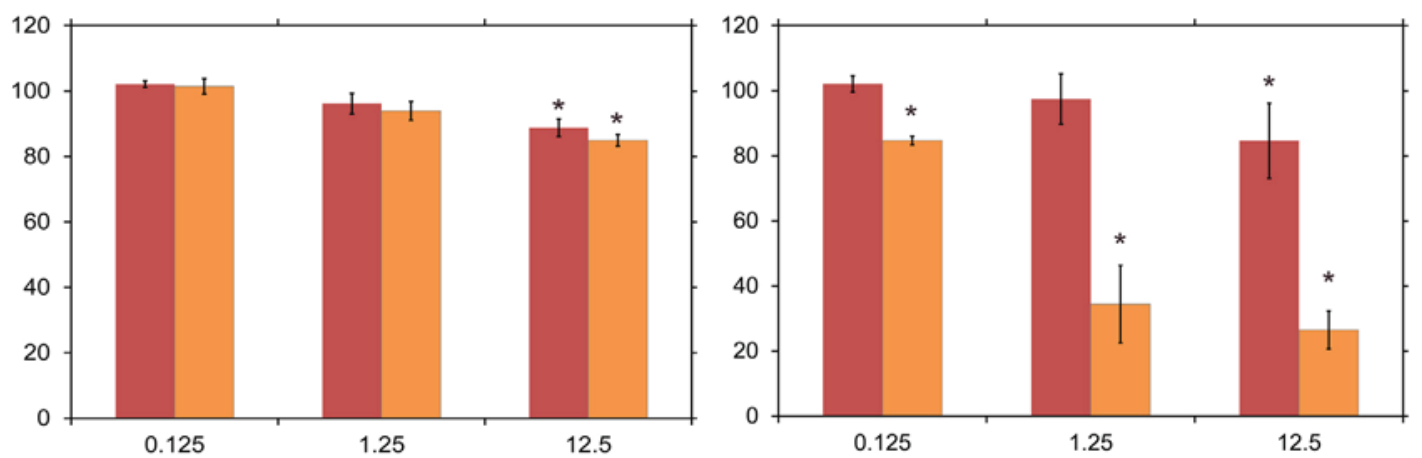

(b)

A549

DNA

RAW 264.7

(e)
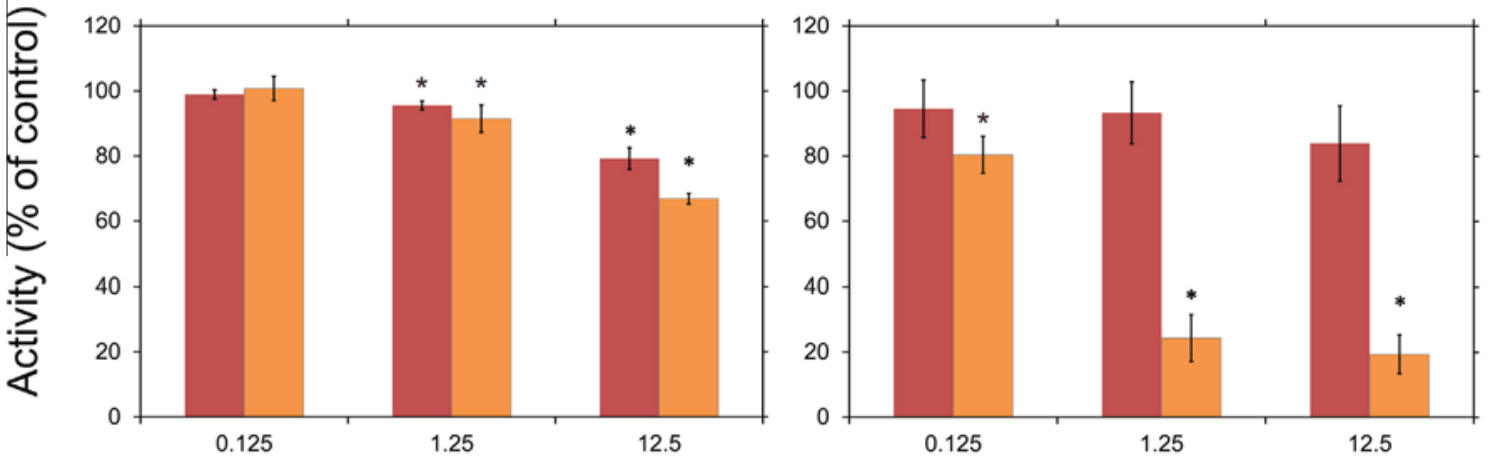

(c)

MTT

RAW 264.7
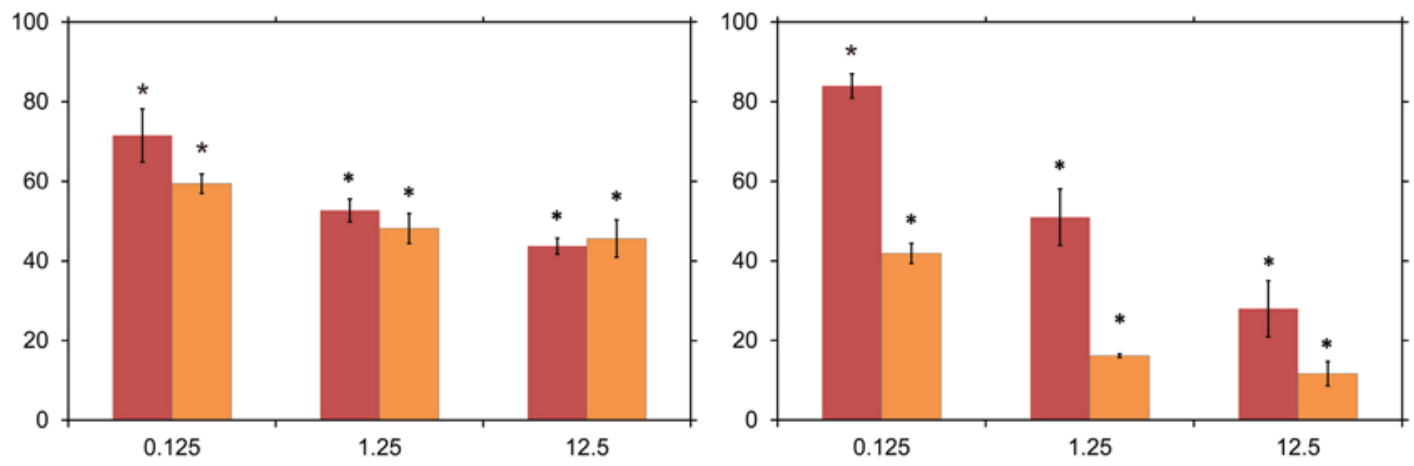

Nanomaterial concentration $\left(\mu \mathrm{g} / \mathrm{cm}^{2}\right)$

: GO

: $\mathrm{f}-\mathrm{CNT}$

Fig. 4 - Effect of nanomaterials on A549 (a-c) and RAW 264.7 (d-f) cells determined by FMCA assays (a, d), DNA assays (b, e) and MTT assays (c, f). Measurements were performed after 5 days of exposure to $0.125,1.25$ and $12.5 \mu \mathrm{g} / \mathrm{cm}^{2} \mathrm{GO}$ and $\mathrm{f}-\mathrm{CNTs}$. Mean \pm standard deviation values from three independent experiments are shown. $\left[^{*} p<0.05\right.$ in comparison to untreated controls]. For each condition and type of assay, the value for untreated control cells was defined as $100 \%$.

of A549 cells. The phagosomes incorporated a considerable amount of GO, often accommodating more than one nanosheet at a time (Fig. 7b-d); the shape of the phagosome was often determined by the rather irregular shape of the engulfed nanomaterial (Fig. 7c-f). In comparison to A549 cells, the total load of GO per RAW 264.7 cell was clearly higher, in line with the principal function of macrophages to phagocyte foreign material. However, with respect to the morphology of other cell organelles (nucleus, mitochondria) RAW 264.7 cells appeared "healthy", i.e., no apparent signs of nuclear shrinkage (pykno- sis) or impaired "swollen" mitochondria. Also no GO was found outside of membrane-enclosed vesicles indicating that in both cell types, GO are taken up by an endocytic pathway.

3.3. Generation of reactive oxygen species (ROS) by graphene oxide

Several studies proposed oxidative stress as a key mechanism involved in the toxicity of various nanomaterials [31,45-47] that results from the imbalance between excessive 
(a) A549

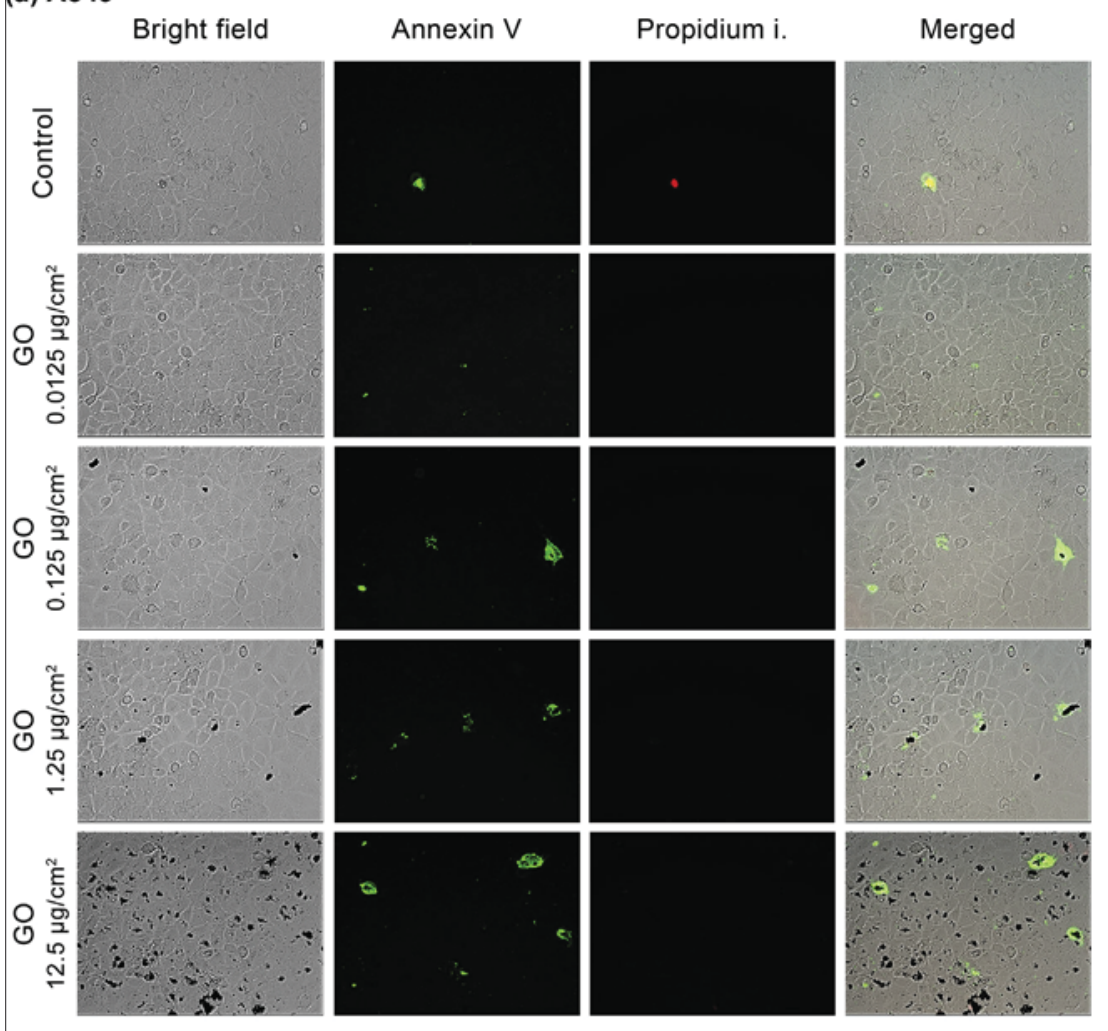

(b) RAW 264.7

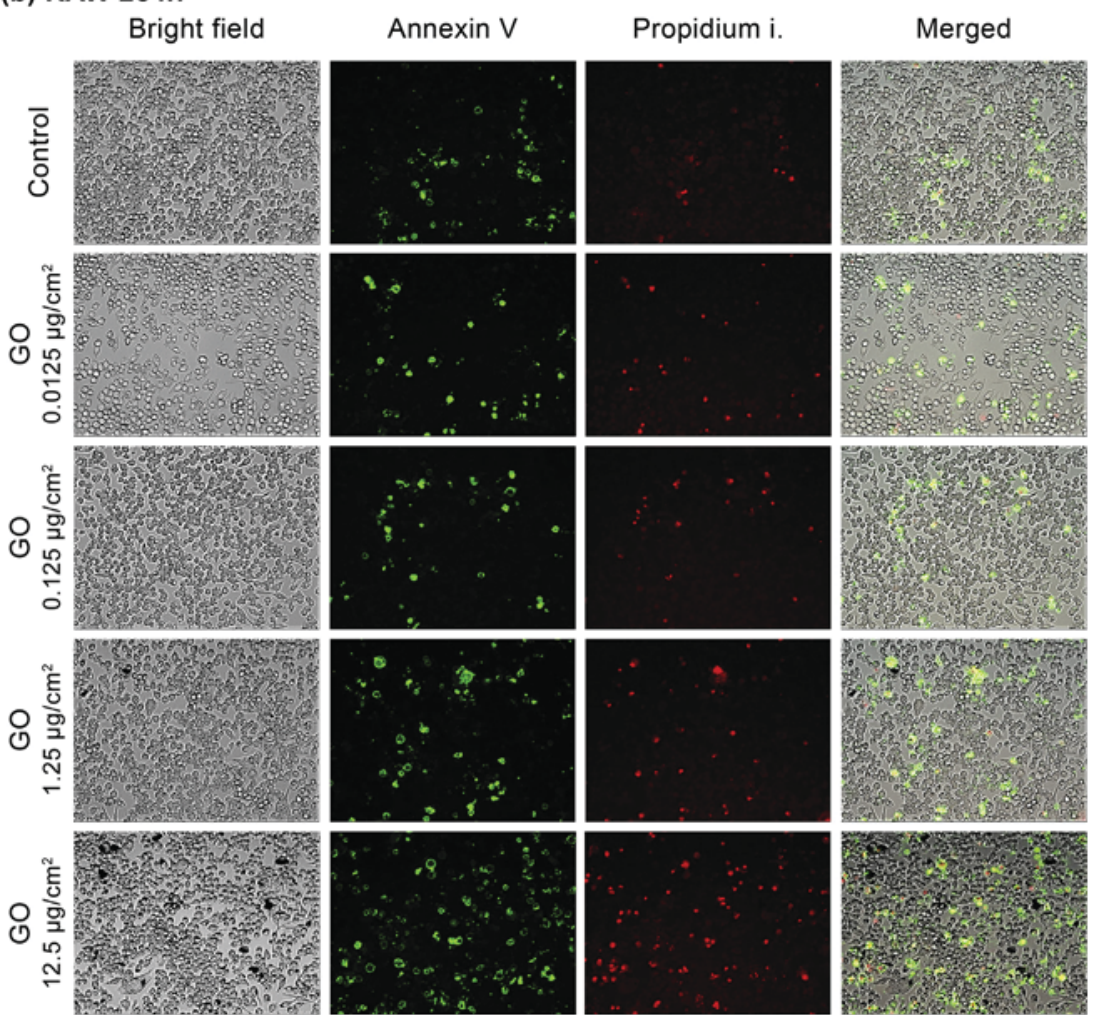

Fig. 5 - Alexa Fluor ${ }^{\circledR} 488$ Annexin V/Dead Cell Apoptosis Assay for A549, epithelial (a) and RAW 264.7, macrophage (b) cells after 4 days of incubation with GO at different concentrations. Representative photomicrographs of control (first row) and treated cells with $0.0125 \mu \mathrm{g} / \mathrm{cm}^{2}$ (second row), $0.125 \mu \mathrm{g} / \mathrm{cm}^{2}$ (third row), $1.25 \mu \mathrm{g} / \mathrm{cm}^{2}$ (fourth row) and $12.5 \mu \mathrm{g} / \mathrm{cm}^{2}$ (fifth row) graphene oxide are shown in panels (a) and (b), respectively. 
generation of ROS and the limited antioxidant defense capacity of cells, thereby leading to adverse biological effects such as damage of biomolecules, e.g., peroxidation of membrane lipids, denaturation of proteins and alterations in DNA. Thus, we aimed to investigate whether GO could cause such an imbalance in A549 and RAW 264.7 cells. They were exposed to the nanomaterial at various concentrations $(0.0125 \mu \mathrm{g} /$ $\mathrm{cm}^{2}-12.5 \mu \mathrm{g} / \mathrm{cm}^{2}$ ) for periods of $30 \mathrm{~min}$ to $24 \mathrm{~h}$. The formation of intracellular ROS was measured by the commonly used DCF assay $[12,31,40,48]$, which is based on the conversion of the non-fluorescent $2^{\prime}, 7^{\prime}$-dichlorodihydrofluorescein diacetate to the highly fluorescent $2^{\prime}, 7^{\prime}$-dichlorofluorescein; the substrate is oxidized preferentially by peroxides [39,49].

GO enhanced the formation of intracellular ROS in both A549 and RAW 264.7 cells at the highest concentration of $12.5 \mu \mathrm{g} / \mathrm{cm}^{2}$ up to 3.5 -times compared to control cells, already after 30 min (Fig. 8a,b). ROS generation was found to be transient and reached a maximum fold-induction within an hour before gradually decreasing. The number of viable A549 and
RAW 264.7 cells evidenced by the FMCA assay was not affected by the addition of GO $\left(12.5 \mu \mathrm{g} / \mathrm{cm}^{2}\right.$; Suppl. Fig. 2) during the period of $24 \mathrm{~h}$. These results were further confirmed by counting viable cells using the Trypan Blue assay (data not shown). Thus, ROS generation is not the result of decreased cell viability. The ROS formation was significantly attenuated when macrophages were co-incubated with $\mathrm{N}$-acetyl-L-cysteine (NAC; $10 \mathrm{mM}$ ) an antioxidant, known as a precursor of glutathione synthesis. This suggests that ROS production is the result of a transient reduction in antioxidant defense of cells exposed to GO. In total four experiments were performed at two different cell densities. In the case of cells plated at higher initial density $\left(8 \times 10^{4}\right.$ cells/well $)$ the fold increase of ROS was reduced from $4.2 \pm 2.4$ to $1.8 \pm 0.5$ (Student's t-test; $p<0.05)$, and at lower cell density $\left(5 \times 10^{4}\right.$ cells/well $)$ from $2.8 \pm 0.35$ to $1.4 \pm 0.09$ (Student's t-test; $p<0.001$ ) after NAC treatment (Suppl. Fig. 3).

After $24 \mathrm{~h}$ a minor ROS accumulation was still observed, but the relative intensity remained close to untreated
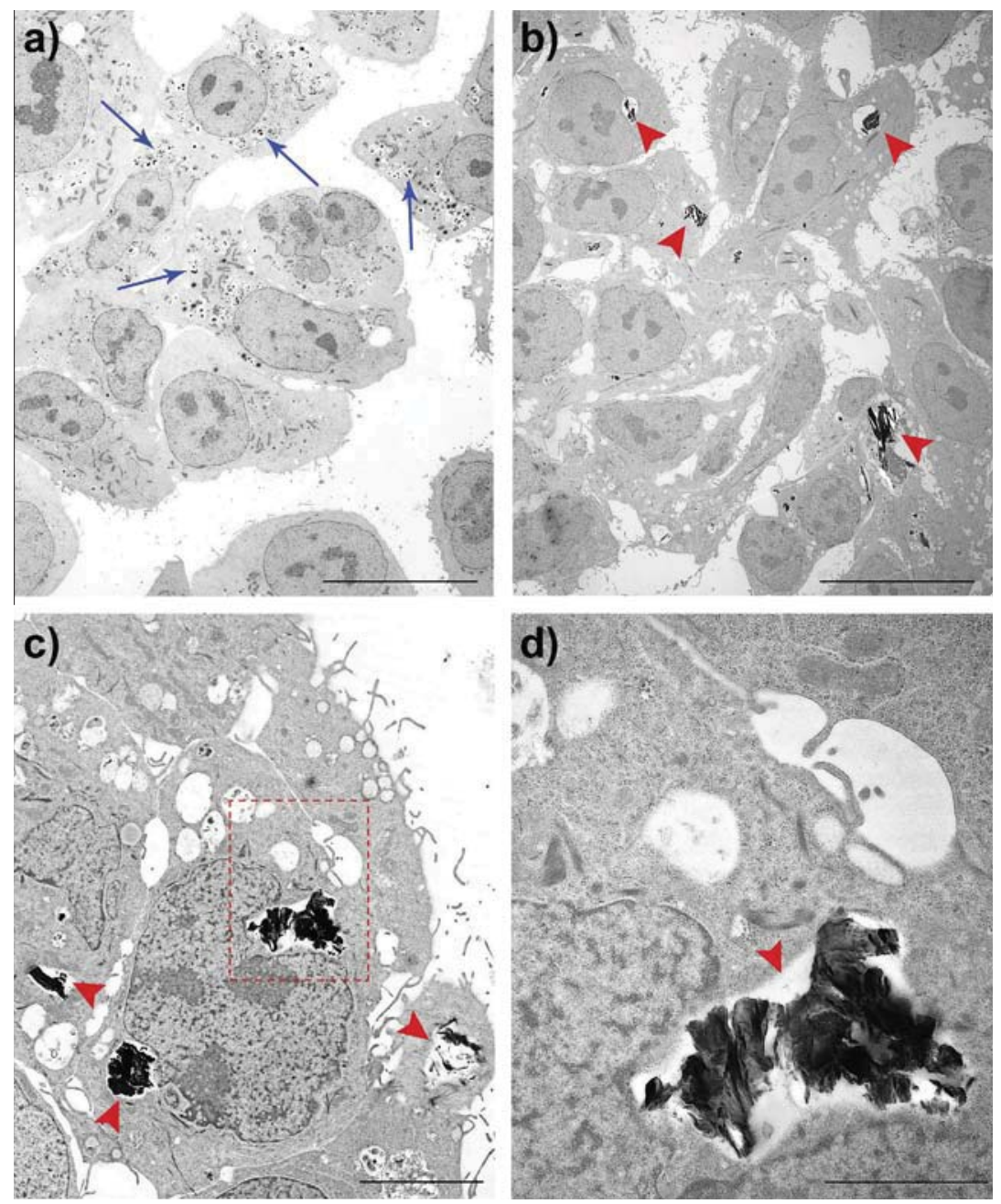

Fig. 6 - Transmission electron micrographs of A549 cells exposed for 4 days to the culture medium alone ((a); blue arrows point to some of the lamellar body structures that are abundant in the cytoplasm) or $12.5 \mu \mathrm{g} / \mathrm{cm}^{2}$ graphene oxide (b-d).

Graphene oxide is internalized by epithelial cells and located within (endo)lysosomal compartments (red arrowheads; b-d). Magnified image of $(c)$ showing the perinuclear area of a cell with a GO-containing lysosome. Scale bars are $20 \mu \mathrm{m}(\mathrm{a}, \mathrm{b}), 5 \mu \mathrm{m}$ (c) and $2 \mu \mathrm{m}$ (d). (For interpretation of the references to colour in this figure legend, the reader is referred to the web version of this article.) 

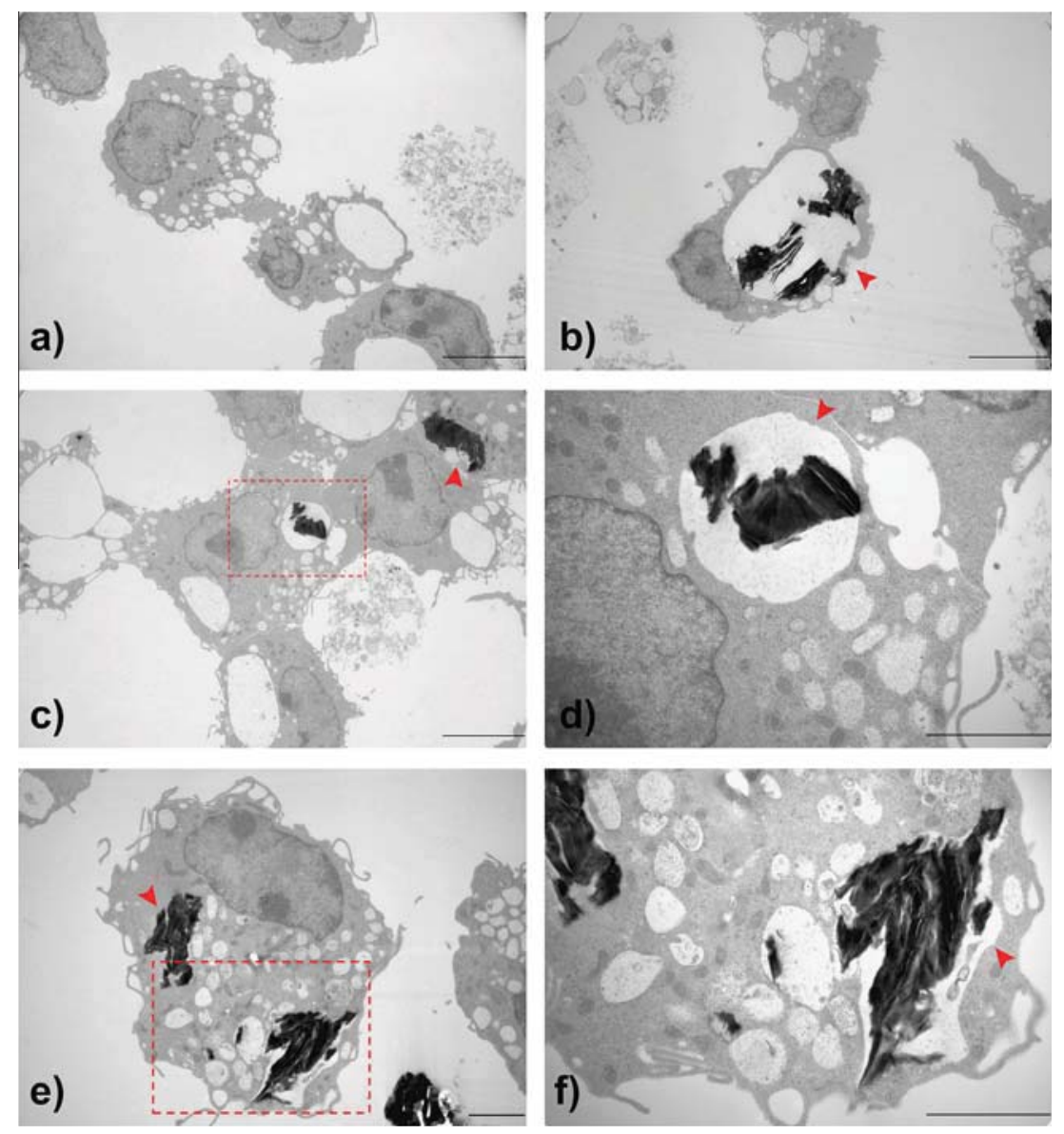

Fig. 7 - Uptake of graphene oxide by RAW 264.7 macrophages: control cells incubated in a cell culture medium (a) and cells incubated for 4 days with $12.5 \mu \mathrm{g} / \mathrm{cm}^{2}$ graphene oxide (b-f). The cells phagocytosed GO; the nanomaterial with lateral dimensions up to several microns is localized in phagocytic vesicles, phagosomes that often occupy a significant volume of the cells (red arrowheads; b-f). The cell region in the inset of the micrographs (c) and (e) is shown at higher magnification in (d) and (f), respectively. Scale bars: $5 \mu \mathrm{m}(\mathrm{a}-\mathrm{c})$ and $2 \mu \mathrm{m}$ (d-f). (For interpretation of the references to colour in this figure legend, the reader is referred to the web version of this article.)

controls. During the first three hours, also at a lower dose of $1.25 \mu \mathrm{g} / \mathrm{cm}^{2} \mathrm{GO}$ an increase in ROS production was observed; however relative values were rarely increased by more than $20 \%$ compared to untreated control cells. The 2 lowest doses did not lead to an imbalance in the redox state of the cells, evidenced by unaltered ROS production compared to untreated cells.

Our results provide evidence on the production of unspecific intracellular ROS during a rather short initial period after GO exposure, mostly evident at the highest dose tested. The fact that GO-mediated increases in ROS levels decline rather fast might be the result of several processes. On the one hand, the GO-mediated increase in ROS production could be eliminated/attenuated by the induction of the radical scavenging system of the cells within $24 \mathrm{~h}$. On the other hand, ROS production could cease caused by the different localization of $\mathrm{GO}$ at a later time point than the one at initial exposure. Moreover, ROS production was not determined at later time points, thus we cannot exclude that continuous GO exposure might trigger a further delayed release of ROS. As mentioned above, the employed method allows for the detection of unspecific ROS (mostly peroxides) formation inside cells; it does not however measure the whole spectrum of ROS, e.g., superoxide anions. Nevertheless, in order to compare our results with previous studies, the DCF assay was selected.

3.4. Comparison of the kinetics of intracellular GO accumulation and intracellular ROS generation

In order to establish a putative mechanistic link between GO uptake and ROS production, we carried out time-lapse TEM experiments using RAW 264.7 macrophages that were exposed to $\mathrm{GO}$ at $12.5 \mu \mathrm{g} / \mathrm{cm}^{2}$ for 1,2 and $3 \mathrm{~h}$, within the time interval, where significant ROS generation has been observed (Fig. 8). The time course for phagocytic uptake of micrometersized particles in macrophages has been reported to occur quickly, generally $50-75 \%$ of the particles are taken up within the first $3 \mathrm{~h}$ following particle deposition [50]. Representative TEM micrographs of GO-treated macrophages for $1-3 \mathrm{~h}$ are shown in Fig. 9. At the earliest time point $(60 \mathrm{~min})$ most of the nanosheets were already in close proximity of the cell membranes and their uptake was initialized as evidenced by the formation of cup-shaped plasma membrane extensions bending over the GO sheets (Fig. 9a). This indicates an 


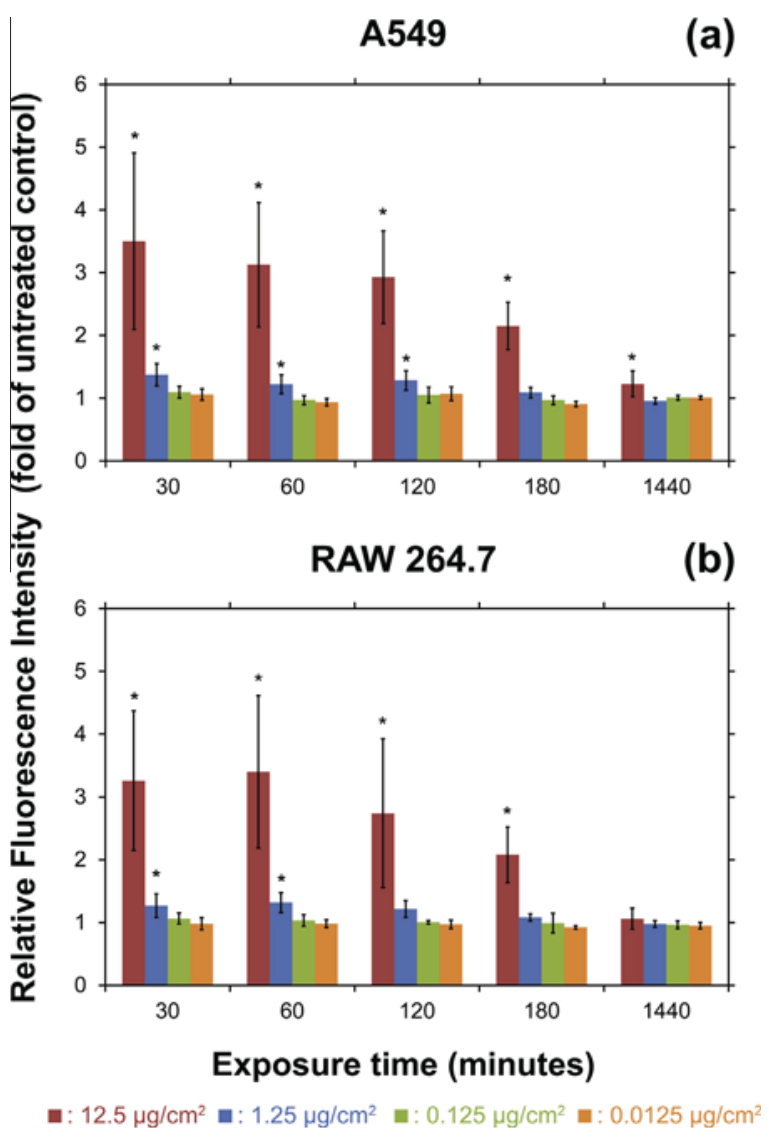

Fig. 8 - Formation of ROS in A549, epithelial (a) and RAW 264.7, macrophage (b) cells after nanomaterial incubation for $30 \mathrm{~min}, 60 \mathrm{~min}, 120 \mathrm{~min}, 180 \mathrm{~min}$ and $24 \mathrm{~h}$. Cells were treated with $0.0125 \mu \mathrm{g} / \mathrm{cm}^{2}, 0.125 \mu \mathrm{g} / \mathrm{cm}^{2}, 1.25 \mu \mathrm{g} / \mathrm{cm}^{2}$ and $12.5 \mu \mathrm{g} / \mathrm{cm}^{2}$ of graphene oxide. ROS were detected by fluorescence measurement of the reporter DCF; the results are expressed as the mean \pm standard deviation of $n \geqslant 4$ independent experiments [ $p<0.05$ in comparison to untreated controls].

active uptake mechanism via phagocytosis and/or macropinocytosis. Due to the heterogeneous size distribution of GO nanosheets ranging from a hundred nanometers to a few micrometers in lateral dimension, both processes can occur in macrophages, the former preferentially in the case of large $(>1 \mu \mathrm{m})$ sheets, while the latter taking place, when they are a few to several hundred nanometers [51]. GO located in intracellular vesicles could be identified only rarely. After the second hour of GO treatment, besides GO interacting with the extracellular layer of the plasma membrane, cells incorporated the material, enclosing them in phagosomes Fig. $9 \mathrm{~d}-\mathrm{f}$. At the latest time point investigated (180 min postexposure), most of the nanomaterial was located within phago(lyso)somes, however GO could still be observed bound to the extracellular leaflet of the cell membrane (Fig. 9g-i).

In comparison, ROS formation peaked within the first hour of GO exposure in RAW 264.7 cells, when GO was rarely observed intracellularly. Our findings hint that the principal triggering signal for the formation of intracellular ROS is the initial interaction between GO and the cell surface upon GO deposition rather than the subsequent internalization of GO. Nevertheless, it is possible that further internalization by endocytic processes contributes to sustaining the disequilibrium in the oxidative status of the cells.

\subsection{Physiological consequences of the cell-nanomaterial interaction}

Our results strongly support the notion that the shape of NM plays a key role in the biological/toxicological responses of cells, in line with previously published studies [12,20]. GO and rGO were found to be less toxic when compared to $\mathrm{f}$ CNT. Nonetheless GD considerably decreased the metabolic activity of NM-exposed cells, at least at the highest doses tested $\left(1.25-12.5 \mu \mathrm{g} / \mathrm{cm}^{2}\right)$. This is the likely result of NM-cell interactions. In addition to hydrophobic graphenic domains, the oxygen-containing groups (hydroxyl, epoxy groups in the plane, carbonyl and carboxyl groups located at the sheet edges [27]) in GO introduce charged and electronegative regions on the surfaces, thus enabling non-covalent interactions between GO and proteins, including formation of hydrogen bonds, electrostatic forces as well as hydrophobic interactions [15,52]. Thus, GO sheets might interact with cell surface receptors in such a way as to either prevent the binding of signaling molecules to these receptors or possibly by mimicking the ligand of a receptor, which then might result in its constitutive activation. In both cases, abnormalities may occur in intracellular signaling pathways that regulate cell growth, proliferation, differentiation or survival. It may also impair trans-membrane proteins acting as transporters for nutrients or other essential biomolecules, thus leading to the decreased metabolic activity observed after GD treatment. In epithelial cells (A549), the reduction in metabolic activity evidenced by the MTT assay rarely caused cells to die, while in macrophages characterized by their high phagocytic capacity, both necrotic and more evident, apoptotic cell death were increased. GO was previously shown to cause morphological changes characteristic for apoptosis in human fibroblast cells (HDF), when added at 100 and $20 \mu \mathrm{g} / \mathrm{mL}$ for 1 and 3 days, respectively. Longer exposure (5 days) yet at a lower dose $(5 \mu \mathrm{g} / \mathrm{mL})$ resulted in unaltered cell morphology [17]. Clearly more studies have focused on the effects of pristine graphene. Pheochromocytoma-derived PC12 cells show evidence of apoptosis through caspase-3 activation after exposure to $100 \mu \mathrm{g} / \mathrm{mL}$ of graphene [12]. Interestingly, only pristine graphene and not carboxyl-functionalized graphene exerted an intracellular stress response in monkey renal cells that induced apoptosis, particularly at higher doses of 100 and $300 \mu \mathrm{g} / \mathrm{mL}$ [53]. Pathways leading to apoptotic cell death in graphene-exposed RAW 264.7 macrophages include the activation of the mitochondrial pathway through the activation of the MAPKs (JNK, ERK and p38) as well as the TGF- $\beta$-related signaling pathways [44]. Thus, in all studies, apoptotic pathways were shown to be relevant for graphene- and GDinduced cytotoxicity. Of note, in the various studies different materials were tested, different doses were applied and various cellular responses were investigated. Similarly to other ENMs, a standardized approach for the in vitro toxicity assessment of GD has not yet been established, which hampers the direct inter-laboratory comparison of the obtained results. 

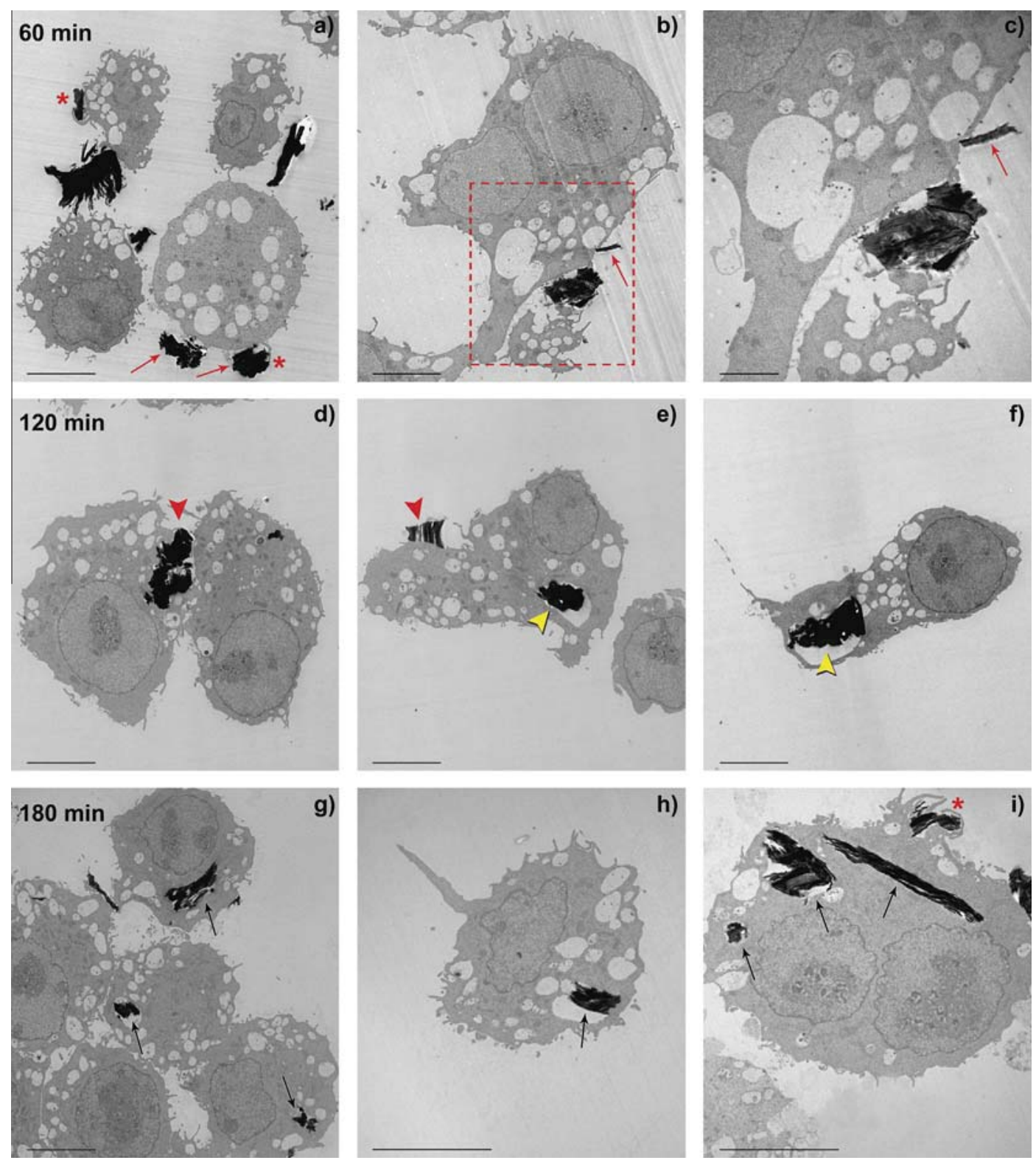

Fig. 9 - Time-lapse experiment showing the initial interaction of graphene oxide (GO) with RAW 264.7 cells, the subsequent uptake and subcellular localization. Macrophages were exposed to $12.5 \mu \mathrm{g} / \mathrm{cm}^{2}$ graphene oxide for $60 \mathrm{~min}(\mathrm{a}-\mathrm{c}), 120 \mathrm{~min}(\mathrm{~d}-\mathrm{f})$ and $180 \mathrm{~min}(\mathrm{~g}-\mathrm{i})$. At the earliest time point $(60 \mathrm{~min})$ most of the nanomaterials are localized outside the cells, getting in close proximity to the cell membrane where the cells start to initialize the uptake (red arrows; a-c). The dotted region of the micrograph in (b) is shown magnified in (c). After two hours of incubation (second row), GO is already observed both in contact with the external side of the cell membrane (red arrowheads; $d$, e) and intracellularly inside phagosomes (yellow arrowheads; e, f). 180 min post-exposure ( $\mathrm{g}-\mathrm{i}$ ) most of the nanomaterial is found to be localized inside the cells clearly confined to membrane-enclosed vesicles (endosomes, endolysosomes; black arrows; g-i). Red asterisks designate areas where the plasma membrane extends over the GO sheets as cup-shaped extensions indicating phagocytosis or macropinocytosis as the uptake mechanism. Scale bars are: $5 \mu \mathrm{m}$ on each micrograph apart from (c), where it corresponds to $2 \mu \mathrm{m}$. (For interpretation of the references to colour in this figure legend, the reader is referred to the web version of this article.)

Only few studies have addressed the question of uptake and subsequent fate of $\mathrm{GO}$. Hu and co-workers suggested internalization of GO nanosheets in A549 cells via endocytosis. GO internalization was observed selectively in macrophages, but not in other non-phagocytic cell types [21]. Our TEM analyses revealed GO nanosheets to be present within vesicular structures in macrophages as well as in cells of epithelial origin (A549), i.e., in both phagocytic and principally non-phagocytic cells, indicative of endocytosis. In support of this proposed mechanism, we observed plasma membrane protrusions surrounding the nanomaterial prior to internalization indicative of an active uptake process by phagocytosis 
and/or macro-pinocytosis. All internalized material was located exclusively in membrane-confined vesicles regardless of GO size; no compartmentalization in other organelles or in the nucleus was observed as previously reported for HDF fibroblast cells [17]. The lateral material dimension was suggested to affect NM uptake, biological effects and also the clearance of the NM [20]. GO with lateral dimensions of either $350 \mathrm{~nm}$ to $2 \mu \mathrm{m}$ were both taken up by macrophages, but only the larger ones increased inflammation cytokine levels (e.g., IL-6, MCP, TNF- $\alpha$ ) in a dose dependent manner [21]. Also graphene-based nanoplatelets are internalized; however if the lateral dimension exceeds $15 \mu \mathrm{m}$, the NM is only partially taken up and induces frustrated phagocytosis in THP-1 cells $[19,20]$. In these cells also the Nalp3 inflammasome is activated as evidenced by increased IL-1 $\beta$ levels. In our study GO with a lateral dimension of up to $5 \mu \mathrm{m}$ was internalized and no evidence of frustrated phagocytosis was found. Moreover, the overall cell morphology and the ultrastructure of the examined cells remained rather similar to the one of untreated cells with the exception of the increased number of NM-containing phagosomes. Nonetheless, it cannot be excluded that in samples exposed for longer periods (4 days), the loosely attached cells with putative abnormalities in their ultrastructure had been washed off during the specimen preparation process.

The most accepted paradigm in nanoparticle toxicology [54] is the oxidative-stress paradigm [55,56], best studied in CNT toxicity [31,45,57-59]. The chemical resemblance of graphene and GO to pristine- and f-CNT, respectively, stimulated researchers to investigate the biological responses of cells with respect to the potential of the graphene family to cause oxidative stress. Recent studies reporting on graphene-related toxicity $[12,20,44,53]$ propose oxidative stress as a potential toxicity pathway, however the toxicological profile of the GD is still to be elucidated.

In line with the above reports, we detected intracellular ROS production upon GO exposure in A549 and RAW 264.7 cells. Within $1 \mathrm{~h}$ of GO exposure, unspecific ROS were produced, in significant amounts only at the highest concentrations investigated. Since at these early time points, internalization of GO is minimal, the interaction of GO nanosheets with the cell surface appears to be the main triggering signal for the formation of the detected radicals. Moreover, we noticed similar kinetics of ROS production upon GO exposure as ROS generation caused by ambient ultrafine particles and polystyrene nanoparticles in RAW 264.7 cells [47]. The authors demonstrated that in addition to peroxides superoxide anions $\left(\mathrm{O}_{2}{ }^{-}\right)$were generated as well. The formation of peroxides commenced early, in less than $1 \mathrm{~h}$ after exposure, and was observed to decline after a few hours, while $\mathrm{O}_{2} \cdot{ }^{-}$production started later and was progressive in nature. Future studies are aimed to investigate whether $\mathrm{O}_{2}{ }^{--}$generation with similar kinetics would also occur after GO exposure.

\section{Conclusions}

Collectively, our results indicate that GO exhibited a mild acute cytotoxic action on both epithelial and macrophage cells, as shown by the quantitative viability tests. An important parameter determining the biological effects of GO is its two-dimensional shape. In contrast to one-dimensional NTs (BNNTs, $\mathrm{TiO}_{2}$ ) that were found throughout the exposed cells, i.e., in the cytoplasm, in organelles including the nucleus $[28,30]$, GO nanosheets were only present in phago(endo)somes not causing any apparent adverse changes in the cellular morphology and ultrastructure. Finally, ROS generation upon GO exposure in the epithelial and macrophage cells may contribute to the short-term cytotoxicity. Yet, it may have a more important role in the later onset of intermediate effects, i.e., genotoxicity as the nanomaterial-induced oxidative stress may induce the expression of pro-inflammatory mediators initiating inflammatory responses in the target cells.

Thus far, the potential health risks associated with GD have only recently become the subject of intensive investigation. The current literature is too limited to reach definitive conclusions about the potential hazards of these technologically relevant nanostructures and is mainly based on in vitro short-term studies (usually limited to $<48 \mathrm{~h}$ ). Furthermore, even less studies addressed the question of the bio-distribution and toxicity in animal models in vivo. The emerging literature on their biomedical applications $[6,7,22,60,61]$ indicates that the use of GD in industrial applications is clearly set to grow in the future. Substantial work remains in elucidating detailed mechanisms of how the relevant parameters (e.g., shape, surface properties) of GD affect humans or animal models, at the cellular level, at the level of organs and ultimately, the whole organism.

\section{Conflict of interest}

The authors report no conflicts of interest. The authors alone are responsible for the content and writing of the paper.

\section{Acknowledgments}

This work was supported by the Swiss National Foundation (project number: 205321-125299/1). L.H. acknowledges the help of Mrs. Brigitte Scolari and Rita Smajda in electron microscopy.

\section{Appendix A. Supplementary data}

Supplementary data associated with this article can be found, in the online version

R E F E R E N C E S

[1] Huang X, Yin Z, Wu S, Qi X, He Q, Zhang Q, et al. Graphenebased materials: synthesis, characterization, properties, and applications. Small 2011;7(14):1876-902.

[2] Stankovich S, Dikin DA, Dommett GHB, Kohlhaas KM, Zimney EJ, Stach EA, et al. Graphene-based composite materials. Nature 2006;442(7100):282-6. 
[3] Paek SM, Yoo E, Honma I. Enhanced cyclic performance and lithium storage capacity of SnO2/graphene nanoporous electrodes with three-dimensionally delaminated flexible structure. Nano Lett 2009;9(1):72-5.

[4] Dikin DA, Stankovich S, Zimney EJ, Piner RD, Dommett GHB, Evmenenko G, et al. Preparation and characterization of graphene oxide paper. Nature 2007;448(7152):457-60.

[5] Yang K, Zhang S, Zhang G, Sun X, Lee ST, Liu Z. Graphene in mice: ultrahigh in vivo tumor uptake and efficient photothermal therapy. Nano Lett 2010;10(9):3318-23.

[6] Yang XY, Zhang XY, Liu ZF, Ma YF, Huang Y, Chen Y. Highefficiency loading and controlled release of doxorubicin hydrochloride on graphene oxide. J Phys Chem C 2008;112(45):17554-8.

[7] Zhang LM, Xia JG, Zhao QH, Liu LW, Zhang ZJ. Functional graphene oxide as a nanocarrier for controlled loading and targeted delivery of mixed anticancer drugs. Small 2010;6(4):537-44.

[8] Zhang XY, Yin JL, Peng C, Hu WQ Zhu ZY, Li WX, et al. Distribution and biocompatibility studies of graphene oxide in mice after intravenous administration. Carbon 2011;49(3):986-95.

[9] Akhavan O, Ghaderi E. Toxicity of graphene and graphene oxide nanowalls against bacteria. ACS Nano 2010;4(10):5731-6.

[10] Hu WB, Peng C, Luo WJ, Lv M, Li XM, Li D, et al. Graphenebased antibacterial paper. ACS Nano 2010;4(7):4317-23.

[11] Ruiz ON, Fernando KAS, Wang BJ, Brown NA, Luo PG, McNamara ND, et al. Graphene oxide: a nonspecific enhancer of cellular growth. ACS Nano 2011;5(10):8100-7.

[12] Zhang Y, Ali SF, Dervishi E, Xu Y, Li Z, Casciano D, et al. Cytotoxicity effects of graphene and single-wall carbon nanotubes in neural phaeochromocytoma-derived PC12 cells. ACS Nano 2010;4(6):3181-6.

[13] Chang Y, Yang ST, Liu JH, Dong E, Wang Y, Cao A, et al. In vitro toxicity evaluation of graphene oxide on A549 cells. Toxicol Lett 2011;200(3):201-10.

[14] Duch MC, Budinger GR, Liang YT, Soberanes S, Urich D, Chiarella SE, et al. Minimizing oxidation and stable nanoscale dispersion improves the biocompatibility of graphene in the lung. Nano Lett 2011;11(12):5201-7.

[15] Hu W, Peng C, Lv M, Li X, Zhang Y, Chen N, et al. Protein corona-mediated mitigation of cytotoxicity of graphene oxide. ACS Nano 2011;5(5):3693-700.

[16] Liao KH, Lin YS, Macosko CW, Haynes CL. Cytotoxicity of graphene oxide and graphene in human erythrocytes and skin fibroblasts. ACS Appl Mater Interfaces 2011;3(7):2607-15.

[17] Wang K, Ruan J, Song H, Zhang JL, Wo Y, Guo SW, et al. Biocompatibility of graphene oxide. Nanoscale Res Lett 2011;6:8.

[18] Singh SK, Singh MK, Nayak MK, Kumari S, Shrivastava S, Gracio JJ, et al. Thrombus inducing property of atomically thin graphene oxide sheets. ACS Nano 2011;5(6):4987-96.

[19] Sanchez VC, Jachak A, Hurt RH, Kane AB. Biological interactions of graphene-family nanomaterials: an interdisciplinary review. Chem Res Toxicol 2012;25(1):15-34.

[20] Schinwald A, Murphy FA, Jones A, MacNee W, Donaldson K. Graphene-based nanoplatelets: a new risk to the respiratory system as a consequence of their unusual aerodynamic properties. ACS Nano 2012;6(1):736-46.

[21] Yue H, Wei W, Yue Z, Wang B, Luo N, Gao Y, et al. The role of the lateral dimension of graphene oxide in the regulation of cellular responses. Biomaterials 2012;33(16):4013-21.

[22] Bao H, Pan Y, Ping Y, Sahoo NG, Wu T, Li L, et al. Chitosanfunctionalized graphene oxide as a nanocarrier for drug and gene delivery. Small 2011;7(11):1569-78.

[23] Hummers WS, Offeman RE. Preparation of graphitic oxide. J Am Chem Soc 1958;80(6). 1339-39.
[24] Oberdorster G. Pulmonary effects of inhaled ultrafine particles. Int Arch Occup Environ Health 2001;74(1):1-8.

[25] Pacile D, Meyer JC, Rodriguez AF, Papagno M, Gomez-Navarro C, Sundaram RS, et al. Electronic properties and atomic structure of graphene oxide membranes. Carbon 2011;49(3):966-72.

[26] Mattevi C, Eda G, Agnoli S, Miller S, Mkhoyan KA, Celik O, et al. Evolution of electrical, chemical, and structural properties of transparent and conducting chemically derived graphene thin films. Adv Funct Mater 2009;19(16):2577-83.

[27] Gomez-Navarro C, Weitz RT, Bittner AM, Scolari M, Mews A, Burghard M, et al. Electronic transport properties of individual chemically reduced graphene oxide sheets. Nano Lett 2007;7(11):3499-503.

[28] Horvath L, Magrez A, Golberg D, Zhi C, Bando Y, Smajda R, et al. In vitro investigation of the cellular toxicity of boron nitride nanotubes. ACS Nano 2011;5(5):3800-10.

[29] Magrez A, Kasas S, Salicio V, Pasquier N, Seo JW, Celio M, et al. Cellular toxicity of carbon-based nanomaterials. Nano Lett 2006;6(6):1121-5.

[30] Magrez A, Horvath L, Smajda R, Salicio V, Pasquier N, Forro L, et al. Cellular toxicity of TiO2-based nanofilaments. ACS Nano 2009;3(8):2274-80.

[31] Pulskamp K, Diabate S, Krug HF. Carbon nanotubes show no sign of acute toxicity but induce intracellular reactive oxygen species in dependence on contaminants. Toxicol Lett 2007;168(1):58-74.

[32] Tabet L, Bussy C, Amara N, Setyan A, Grodet A, Rossi MJ, et al. Adverse effects of industrial multiwalled carbon nanotubes on human pulmonary cells. J Toxicol Environ Health A 2009;72(2):60-73.

[33] Mosmann T. Rapid colorimetric assay for cellular growth and survival: application to proliferation and cytotoxicity assays. J Immunol Methods 1983;65(1-2):55-63.

[34] Worle-Knirsch JM, Pulskamp K, Krug HF. Oops they did it again! Carbon nanotubes hoax scientists in viability assays. Nano Lett 2006;6(6):1261-8.

[35] Rago R, Mitchen J, Wilding G. DNA fluorometric assay in 96well tissue culture plates using Hoechst 33258 after cell lysis by freezing in distilled water. Anal Biochem 1990;191(1):31-4.

[36] Lindhagen E, Nygren P, Larsson R. The fluorometric microculture cytotoxicity assay. Nat Protoc 2008;3(8):1364-9.

[37] Larsson R, Kristensen J, Sandberg C, Nygren P. Laboratory determination of chemotherapeutic drug resistance in tumor cells from patients with leukemia, using a fluorometric microculture cytotoxicity assay (FMCA). Int J Cancer 1992;50(2):177-85.

[38] Larsson R, Nygren P, Ekberg M, Slater L. Chemotherapeutic drug sensitivity testing of human leukemia cells in vitro using a semiautomated fluorometric assay. Leukemia 1990;4(8):567-71.

[39] Wan CP, Myung E, Lau BH. An automated micro-fluorometric assay for monitoring oxidative burst activity of phagocytes. J Immunol Methods 1993;159(1-2):131-8.

[40] Kang JL, Moon C, Lee HS, Lee HW, Park EM, Kim HS, et al. Comparison of the biological activity between ultrafine and fine titanium dioxide particles in RAW 264. 7 cells associated with oxidative stress. J Toxicol Environ Health A 2008;71(8):478-85.

[41] Horvath L, Magrez A, Forro L, Schwaller B. Cell type dependence of carbon based nanomaterial toxicity. Phys Status Solidi B 2010;247(11-12):3059-62.

[42] Gangwal S, Brown JS, Wang A, Houck KA, Dix DJ, Kavlock RJ, et al. Informing selection of nanomaterial concentrations for ToxCast in vitro testing based on occupational exposure potential. Environ Health Perspect 2011;119(11):1539-46.

[43] Jin Z, El-Deiry WS. Overview of cell death signaling pathways. Cancer Biol Ther 2005;4(2):139-63. 
[44] Li Y, Liu Y, Fu Y, Wei T, Le Guyader L, Gao G, et al. The triggering of apoptosis in macrophages by pristine graphene through the MAPK and TGF-beta signaling pathways. Biomaterials 2012;33(2):402-11.

[45] Manna SK, Sarkar S, Barr J, Wise K, Barrera EV, Jejelowo O, et al. Single-walled carbon nanotube induces oxidative stress and activates nuclear transcription factor-kappaB in human keratinocytes. Nano Lett 2005;5(9):1676-84.

[46] Oberdorster G, Oberdorster E, Oberdorster J. Nanotoxicology: an emerging discipline evolving from studies of ultrafine particles. Environ Health Perspect 2005;113(7):823-39.

[47] Xia T, Kovochich M, Brant J, Hotze M, Sempf J, Oberley T, et al. Comparison of the abilities of ambient and manufactured nanoparticles to induce cellular toxicity according to an oxidative stress paradigm. Nano Lett 2006;6(8):1794-807.

[48] Konczol M, Ebeling S, Goldenberg E, Treude F, Gminski R, Giere R, et al. Cytotoxicity and genotoxicity of sizefractionated iron oxide (magnetite) in A549 human lung epithelial cells: role of ROS, JNK, and NF-kappaB. Chem Res Toxicol 2011;24(9):1460-75.

[49] Xia Y. Nanomaterials at work in biomedical research. Nat Mater 2008;7(10):758-60.

[50] Geiser M. Update on macrophage clearance of inhaled microand nanoparticles. J Aerosol Med Pulmonary Drug Deliv 2010;23(4):207-17.

[51] Zhao F, Zhao Y, Liu Y, Chang X, Chen C, Zhao Y. Cellular uptake, intracellular trafficking, and cytotoxicity of nanomaterials. Small 2011;7(10):1322-37.

[52] Shi XT, Chang HX, Chen S, Lai C, Khademhosseini A, Wu HK. Regulating cellular behavior on few-layer reduced graphene oxide films with well-controlled reduction states. Adv Funct Mater 2012;22(4):751-9.
[53] Sasidharan A, Panchakarla LS, Chandran P, Menon D, Nair S, Rao CN, et al. Differential nano-bio interactions and toxicity effects of pristine versus functionalized graphene. Nanoscale 2011;3(6):2461-4.

[54] Wick P, Clift MJ, Rosslein M, Rothen-Rutishauser B. A brief summary of carbon nanotubes science and technology: a health and safety perspective. ChemSusChem 2011;4(7):905-11.

[55] Donaldson K, Stone V, Borm PJ, Jimenez LA, Gilmour PS, Schins RP, et al. Oxidative stress and calcium signaling in the adverse effects of environmental particles (PM10). Free Radic Biol Med 2003;34(11):1369-82.

[56] Nel A, Xia T, Madler L, Li N. Toxic potential of materials at the nanolevel. Science 2006;311(5761):622-7.

[57] Shvedova AA, Castranova V, Kisin ER, Schwegler-Berry D, Murray AR, Gandelsman VZ, et al. Exposure to carbon nanotube material: assessment of nanotube cytotoxicity using human keratinocyte cells. J Toxicol Environ Health A 2003;66(20):1909-26.

[58] Shvedova AA, Kisin ER, Murray AR, Gorelik O, Arepalli S, Castranova V, et al. Vitamin E deficiency enhances pulmonary inflammatory response and oxidative stress induced by single-walled carbon nanotubes in C57BL/6 mice. Toxicol Appl Pharmacol 2007;221(3):339-48.

[59] Shvedova AA, Pietroiusti A, Fadeel B, Kagan VE. Mechanisms of carbon nanotube-induced toxicity: focus on oxidative stress. Toxicol Appl Pharmacol 2012;261(2):121-33.

[60] Kalbacova M, Broz A, Kong J, Kalbac M. Graphene substrates promote adherence of human osteoblasts and mesenchymal stromal cells. Carbon 2010;48(15):4323-9.

[61] Liu Z, Robinson JT, Sun XM, Dai HJ. PEGylated nanographene oxide for delivery of water-insoluble cancer drugs. J Am Chem Soc 2008;130(33):10876-7. 